\title{
ESTADO ACTUAL DE LA INVESTIGACIÓN SOBRE PLAGUICIDAS EN MÉXICO
}

\author{
Jaqueline GARCÍA HERNÁNDEZ ${ }^{1}$, José Belisario LEYVA MORALES ${ }^{2}$, \\ Irma Eugenia MARTÍNEZ RODRÍGUEZ ${ }^{3}$, María Isabel HERNÁNDEZ OCHOA ${ }^{4}$, \\ María Lourdes ALDANA MADRID ${ }^{5}$, Aurora Elizabeth ROJAS GARCÍA ${ }^{6}$, \\ Miguel BETANCOURT LOZANO ${ }^{3}$, Norma Elena PEREZ HERRERA ${ }^{7}$ \\ y Javier Humberto PERERA RIOS ${ }^{7}$
}

${ }^{1}$ Laboratorio de Ciencias Ambientales, Centro de Investigación en Alimentación y Desarrollo A.C. (CIAD) Coordinación Guaymas, Carr. Al Varadero Nal. Km 6.6, Guaymas, Sonora, México, C.P. 85480

${ }^{2}$ Centro Nayarita de Innovación y Transferencia de Tecnología, A.C. (CENITT), Cátedras CONACYT-Universidad Autónoma de Nayarit, Secretaría de Investigación y Posgrado. Av. Emilio M. González S/N, Col. Cd. Industrial, Tepic, Nayarit, México C.P. 63173

${ }^{3}$ Laboratorio de Ecotoxicología, Centro de Investigación en Alimentación y Desarrollo A.C. (CIAD) Coordinación Mazatlán, Av. Sábalo Cerritos, C.P. 82100, Mazatlán, Sinaloa

${ }^{4}$ Departamento de Toxicología, Centro de Investigación y de Estudios Avanzados del Instituto Politécnico Nacional (Cinvestav), Instituto Politécnico Nacional 2508, Col. San Pedro Zacatenco, Ciudad de México, México C.P. 07360

${ }^{5}$ Departamento de Investigación y Posgrado en Alimentos, Universidad de Sonora. Rosales y Blvd. Luis Encinas s/n. Centro. Hermosillo, Sonora, México. C.P. 83000

${ }^{6}$ Secretaría de Investigación y Posgrado, Universidad Autónoma de Nayarit. Ciudad de la Cultura Amado Nervo, Tepic, Nayarit. México. C.P. 63155

${ }^{7}$ Unidad Interinstitucional de Investigación Clínica y Epidemiologia, Facultad de Medicina Universidad Autónoma de Yucatán. Avenida Itzáes No. 498 x 59 y 59A Col. Centro, C.P. 97000, Mérida, Yucatán, México

*Autor para correspondencia: jaqueline@ciad.mx

(Recibido enero 2017; aceptado septiembre 2017)

Palabras Clave: patrón de uso, exposición laboral, ecosistemas, contaminación, agricultura

\section{RESUMEN}

El presente trabajo analiza la investigación que se ha llevado a cabo en México con relación al uso y efecto de los plaguicidas en el ambiente y salud humana. Se revisaron 394 artículos publicados en los últimos 20 años en revistas indizadas o arbitradas. Las publicaciones se agruparon en 7 temas principales: 1) patrón de uso de plaguicidas, 2) efectos en el ambiente; 3) estudios ecotoxicológicos; 4) exposición en población humana; 5) residuos en alimentos; 6) toxicología de plaguicidas (estudios in vitro e in vivo); y 7) bioplaguicidas y biorremediación. El análisis de estas investigaciones indican que actualmente se utilizan Plaguicidas Altamente Peligrosos (PAPs) en las zonas agrícolas del país, su uso histórico y actual se relaciona con efectos negativos en ecosistemas terrestres y costeros, se han reportado efectos en la salud de los trabajadores agrícolas y sus familias, tales como alteraciones hematológicas, hormonales, daños genéticos, alteraciones del comportamiento y daños celulares; los niños constituyen el grupo más vulnerable a la exposición, además se han documentado daños genéticos, reproductivos y neuronales en modelos celulares y en organismos de laboratorio y se reportan residuos en alimentos como leche, hortalizas y granos. Como medidas de mitigación, se documentan procesos de biorremediación de suelos y agua contaminada, 
así como el uso de bioplaguicidas. La recomendación principal de este trabajo para las autoridades regulatorias y los tomadores de decisiones, es la implementación de programas de registro de plaguicidas (tipo y volumen) utilizados en prácticas agrícolas y control de vectores de enfermedades, como punto de partida para dimensionar la problemática ambiental y de salud humana que representa el uso actual e histórico de plaguicidas en México.

Keywords: use pattern, work related exposure, ecosystems, pollution, agriculture

\begin{abstract}
This article reports research in the area of use and effects of pesticides in the environment and on human health in Mexico. A total of 394 articles published in the last 20 years in indexed or refereed journals were reviewed. Publications were grouped into 7 main subjects: 1) pesticide use pattern; 2) effects in the environment, 3) ecotoxicological studies; 4) human exposure; 5) residues in food; 6) pesticide toxicology (in vitro and in vivo studies); and 7) biopesticides and bioremediation. The analysis of these publications indicate that Highly Hazardous Pesticides (HHPs) are currently used in agricultural areas, also historical and current use had negative effects in terrestrial and coastal ecosystems. Health effects of agricultural workers and their families have been reported, such as hematological and hormonal alterations, genetic damage, behavioral alterations and cellular damage; children are the most vulnerable group of pesticides exposure; genetic, reproductive and nervous damage have been documented in cellular models and laboratory organisms and pesticide residues in milk, produce and grains have been detected. Bioremediation of contaminated soil and water as well as the use of biopesticides were reported as mitigation measures. The main recommendation of this work for the enforcement agencies and decision makers is the implementation of a pesticide registry program (type and volume) used in agriculture practices and disease control vectors, as a starting point in order to accurately measure the environmental and human health impacts that current and historical use of pesticides represent in Mexico.
\end{abstract}

\section{INTRODUCCIÓN}

Actualmente a nivel mundial están registrados 6400 ingredientes activos correspondientes a plaguicidas que al combinarse con compuestos "inertes" resultan en más de 100000 productos comerciales (Kegley et al. 2016). La mayoría de los compuestos utilizados actualmente se desarrollaron hace más de 70 años, debido a que durante la Segunda Guerra Mundial se generó un desabasto de plaguicidas de origen natural como el extracto de piretro y la nicotina, lo que impulsó la manufactura de productos industriales con estas propiedades (Plimmer 2001).

La síntesis de los primeros plaguicidas como el hexaclorociclohexano $(\mathrm{HCH})$ y el 1,1,1-tricloro-2,2bis(4-clorofenil)-etano, mejor conocido como DDT, data de esta época ya que fueron utilizados para el combate de vectores transmisores de enfermedades como la fiebre tifoidea y el paludismo (Plimmer 2001). También surgieron otros compuestos como los primeros carbamatos (CA) y los primeros organofosforados (OF). En 1944 se comercializó en Alemania el primer OF, bladán, que contenía tetraetil pirofosfato (TEPP) y poco después se desarrolló el paratión, ambos con alta toxicidad en mamíferos (Eto 1974). En 1958 se desarrollaron los herbicidas como el ácido 2,4-diclorofenoxiacético (2,4-D) y la atrazina. Posteriormente se sintetizaron compuestos aparentemente con un índice menor de toxicidad al sustituir el grupo arilo en compuestos aromáticos heterocíclicos, los cuales se utilizaron como insecticidas, fungicidas y reguladores del crecimiento (Eto 1974, Plimmer 2001).

En la década de los ochenta se desarrollaron plaguicidas con mecanismos de acción específicos y se introdujeron nuevas tecnologías de síntesis como la química combinatoria que genera un gran número de nuevos compuestos (Plimmer 2001). En los últimos años el avance en la biotecnología también ha generado nuevos productos que incluyen semillas 
genéticamente modificadas para resistir ciertos herbicidas, la introducción en los cultivos de genes responsables de producir toxinas con propiedades insecticidas, y la generación de plantas resistentes a nemátodos (Plimmer 2001).

La Organización de las Naciones Unidas para la Alimentación y la Agricultura (FAO 2015) reportó que en el año 2013 se obtuvo una producción agrícola a nivel mundial de 23.34 billones de toneladas (t); para lo cual se aplicaron 1.29 millones de $\mathrm{t}$ de plaguicidas (insecticidas, herbicidas, fungicidas y bactericidas). En México se estima que en 2007 se comercializaron $100000 \mathrm{t}$ de estos compuestos, equivalentes al $4 \%$ del consumo mundial (FAO 2017). Sin embargo, no se cuenta con información detallada sobre el grupo o los ingredientes activos más utilizados, mucho menos sobre el uso por Estado de la República o por cultivo. No obstante, la Dirección General de Epidemiología (DGE 2017) reportó alrededor de 4,000 casos de intoxicaciones por plaguicidas en 2016.

Por lo tanto, es necesario contar con una línea base sobre el patrón de uso de estos compuestos en el país, así como de sus efectos en la salud ambiental y humana que muestren la magnitud del problema que representa el uso actual y pasado de los plaguicidas en México.

La presente revisión tiene como objetivo principal, mostrar el estado del arte sobre la investigación y conocimiento de plaguicidas en México, desde su uso hasta los posibles efectos sobre el ambiente y la salud humana.

\section{METODOLOGÍA}

Se realizó una revisión sistemática de 394 artículos con temas relacionados al uso de plaguicidas en México y sus efectos en la salud, ambiente y otros temas, los cuales fueron publicados en los últimos 20 años en revistas indizadas o arbitradas disponibles en internet. Estas publicaciones fueron realizadas por autores de Universidades, Centros de Investigación y de Salud Pública de México. Las herramientas de búsqueda utilizadas fueron https://www.ebscohost. com/ y https://www.ncbi.nlm.nih.gov, mientras que las palabras clave en la búsqueda fueron "pesticides", "health", "environment" y "Mexico". Posteriormente, los artículos se agruparon de acuerdo a la temática tal como se muestra en la figura 1 y se realizó una revisión de su contenido. Para efecto de comparación, los ingredientes activos de los plaguicidas (i.a), se presentan en $\mu \mathrm{g} / \mathrm{g}(\mathrm{ppm})$ de peso seco o en base lipídica para tejido y plasma, respectivamente, y peso seco para sedimento o suelo. En las diferentes secciones se consideraron los valores máximos detectados, ya que de esta manera se identifica el problema más crítico o agudo dentro de un ecosistema o grupo de población.

Si bien la revisión bibliográfica fue exhaustiva, es probable que no se haya incluido toda la literatura relevante en cada tema, por lo que esta revisión representa una línea base general de la cual puedan partir revisiones más profundas de cada tema u otros no considerados.

\section{RESULTADOS}

De acuerdo a la revisión bibliográfica realizada de publicaciones indizadas o arbitradas, se obtuvo un mayor porcentaje de publicaciones en el tema de exposición en población humana (32\%), seguido de efectos en el ambiente (20\%), estudios toxicológicos in vitro e in vivo (14\%), estudios ecotoxicológicos (13\%), bioplaguicidas y biorremediación (13\%), residuos en alimentos $(6 \%)$ y finalmente patrón de uso de plaguicidas (2\%) (Fig. 1). A continuación, se hace una descripción de los principales resultados y conclusiones de estas publicaciones, agrupados por temas y subtemas de interés.

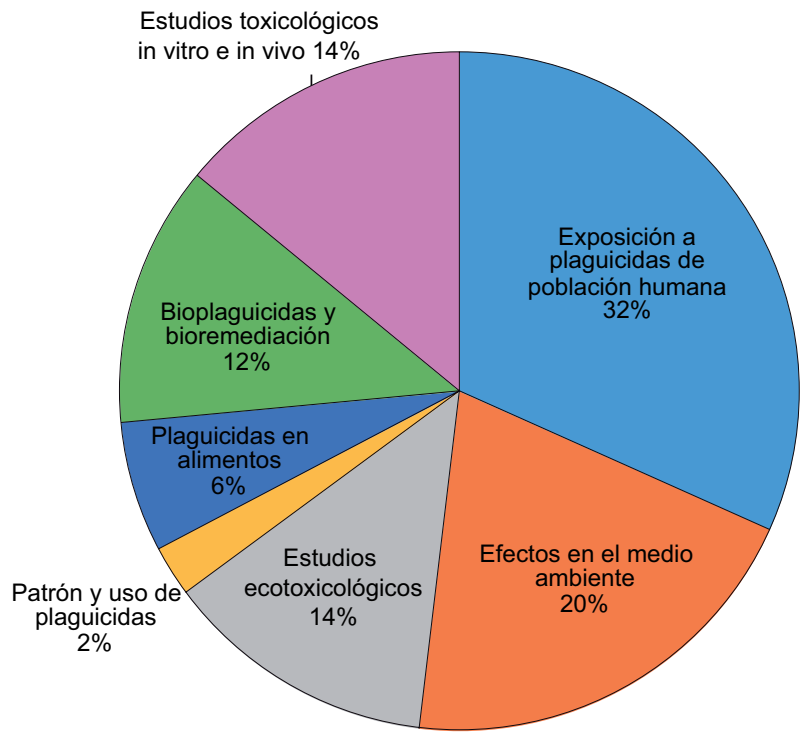

Fig. 1. Proporción de artículos indizados o arbitrados revisados, separados por temática

\section{Patrón de uso de plaguicidas}

Existe poca información publicada sobre los patrones de uso de plaguicidas en las prácticas agrícolas a nivel nacional. Sin embargo, hay estudios puntuales 
que reportan su uso en Campeche, Chiapas, Estado de México, Morelos, Nayarit, Puebla, Sinaloa, Sonora, Tabasco, Tamaulipas, Veracruz y Yucatán. La mayoría de las publicaciones son reportes cualitativos del uso de plaguicidas obtenidos mediante entrevistas. Los pocos reportes cuantitativos son estimaciones basadas en ventas, en conteo de envases vacíos y/o en entrevistas, ya que no existen estadísticas nacionales del uso de agroquímicos.

En el estado de Nayarit y durante el período 2007-2008, González-Arias et al. (2010) realizaron encuestas a los responsables de los establecimientos de venta agroquímicos en los veinte municipios de Nayarit. Los resultados de las encuestas indicaron que existe un mayor uso de plaguicidas en general en la zona norte y centro del estado y un mayor uso de insecticidas (45.9\%), seguido de herbicidas $(30.5 \%)$ y fungicidas $(20.1 \%)$. De acuerdo a la clasificación por grupos químicos los insecticidas más vendidos fueron los OF (50\%), seguido por los piretroides sintéticos (PS) (20\%), CA (8\%), organoclorados (OC) $(8 \%)$ y otros $(14 \%)$. Los ingredientes activos más utilizados pertenecientes al grupo de los OF fueron clorpirifos, metamidofos y paratión metílico; de PS fueron cipermetrina, permetrina y lambda cialotrina; de CA fueron carbofurán, metomilo y oxamilo y de OC, dicofol y endosulfán. En cuanto a herbicidas, los grupos más comercializados fueron las fosfonometilglicinas, clorofenoxis y bipiridilos, mientras que los fungicidas de mayor frecuencia de uso fueron los benzimidazoles, ditiocarbamatos e inorgánicos. González-Arias et al. (2010) encontraron una relación entre el número de intoxicaciones y la venta de productos clasificados por la Organización Mundial de la Salud (OMS) en las categorías Ia (extremadamente peligrosos) y $I b$ (altamente peligrosos).

En el Valle agrícola de Culiacán, Sinaloa, LeyvaMorales et al. (2014) realizaron un inventario de los envases vacíos que se recibieron en un centro de acopio y se obtuvieron bitácoras de aplicación de empresas agrícolas en 2011 y 2012. De acuerdo a los datos de envases vacíos, los autores reportaron un uso aproximado de $78 \mathrm{t}$ de i.a. registradas en las bitácoras, estimando un uso de 223 t de i.a. anuales. En ambos casos (inventarios y bitácoras) se identificaron 59 grupos químicos, siendo los dominantes los ditiocarbamatos, bipiridilos, OF y OC. En relación al tipo de uso, el inventario registró un mayor uso de fungicidas (48\%), seguidos de herbicidas $(26.5 \%)$, insecticidas $(18.8 \%)$ y otros $(6.3 \%)$, mientras que las bitácoras registraron además el uso de nematicidas (19.2\%). De acuerdo a los autores, un $25 \%$ de los i.a. de mayor aplicación (cadusafos, metamidofos, metomilo y oxamilo) corresponden a la categoría $\mathrm{Ib}$ de la OMS.

Hernández-Antonio y Hansen (2011) entrevistaron al personal de la Comisión Nacional del Agua (CONAGUA), de Sanidad Vegetal, del Centro de Apoyo al Desarrollo Rural (CADER), y de la Asociación de Agricultores y Distribuidores de Agroquímicos, para establecer el inventario del uso de plaguicidas en Guasave, Sinaloa. Se observó que entre 2007 y 2008 se aplicaron un total de $707 \mathrm{t}$ de i.a., siendo los OF los más utilizados (300 t/año), seguido de la sal de ácido benzoico (270 t/año) y clorofenoxi (250 t/año). Asimismo, los i.a. más utilizados fueron clorpirifos etil (156 t), dicamba (278 t) y 2,4-D (245 t).

Por otro lado, García-Hernández et al. (2017) obtuvieron por parte del Distrito de Desarrollo Rural 148 (Cajeme) las bases de datos de las ventas de agroquímicos reportadas por las distribuidoras del Valle del Yaqui, Sonora durante el período 2009 -2010. Los autores reportaron un uso anual de $270 \mathrm{t}$ de i.a., con un mayor uso de fungicidas $(40 \%)$ seguido de insecticidas $(35 \%)$ y herbicidas $(25 \%)$, mientras que los grupos químicos más utilizadas fueron $\mathrm{OF}$ seguidos de ditiocarbamatos, PS y OC. Los i.a. más utilizados fueron el mancozeb (uso anual estimado de $26 \mathrm{t}$ ), dimetoato $(25 \mathrm{t})$ y paratión metílico $(15 \mathrm{t})$.

Por su parte, Ortega-Martínez et al. (2014) establecieron un patrón de uso en cultivos de tomate de Chignahuapan, Puebla por medio de entrevistas a trabajadores. En esa región, los agroquímicos más utilizados en 2011 fueron los fungicidas (63\%), seguido de insecticidas (29\%), herbicidas (4\%) y otros (4\%). El grupo de los CA y ditiocarbamatos, fueron los más utilizados, aunque no se especificó su frecuencia, seguido de los compuestos de cobre, PS y otros. Los compuestos empleados con mayor frecuencia se clasificaron como poco probable de presentar riesgo agudo en uso normal, seguido de los moderadamente tóxicos, según la clasificación de la OMS. Sin embargo, los autores mencionan que el $38 \%$ de los trabajadores indicó el uso de paratión metílico, mientras que el $89 \%$ indicó el uso de carbofurán, ambos clasificados como altamente tóxicos.

En invernaderos de floricultivo de Morelos (Cuernavaca, Cuautla, Jiutepec y Temixco), Schilmann et al. (2009) aplicaron cuestionarios a los encargados de la compra de agroquímicos o a los dueños de los invernaderos, durante 2005. Se identificaron 23 i.a. Los insecticidas más utilizados fueron: endosulfán, diazinón, metamidofos, ometoato, paratión metílico, carbofurán, metomilo, oxamilo, bifentrina, permetrina, imidacloprid y abermectina. Los fungicidas reportados fueron: benomil, carbendazim, metil 
tiofanato, mancozeb, triadimefon, captán, clorotalonil, iprodione, triforine, y metalaxil. El único herbicida utilizado fue el glifosato. Además, el insecticida más ampliamente utilizado fue la abamectina, mientras que el fungicida fue el mancozeb. En este estudio los autores enfatizaron los efectos interactivos de la mezcla de productos en la salud de los trabajadores.

En el sureste de México, Pérez-Herrera et al. (2008), reportaron el uso de 29 i.a. en una comunidad agrícola de Yucatán, entre los que se encontraron OF (metamidofos, clorpirifos, paratión metílico y diazinón), CA (metomilo, carbofurán, carbarilo, mancozeb y benomil), PS (permetrina, cipermetrina y lambda cialotrina) y herbicidas (paraquat, 2,4-D amina y glifosato).

De acuerdo con Bejarano (2017) en México están autorizados 183 i.a. de Plaguicidas Altamente Peligrosos (PAPs) los cuales representan el $33 \%$ de los i.a. publicados en el Catálogo Oficial de Plaguicidas (CICOPLAFEST 2016). Estos i.a. se pueden clasificar como extremadamente peligrosos, mortal si es inhalado, carcinógeno, probable carcinógeno, mutagénico, tóxico en reproducción, perturbador endócrino, muy bioacumulable, muy persistente en agua, suelo o sedimento, muy tóxico en organismos acuáticos, muy tóxico en abejas, o inclusión en convenios ambientales vinculantes.

En el Valle de Culiacán, un $53 \%$ de los productos que se utilizan corresponden a la categoría de PAPs y se citan mancozeb, paraquat y clorotalonil como los de mayor uso (Leyva-Morales et al. 2017a). En el Valle del Yaqui, el $43 \%$ de los productos utilizados son PAPs y se citan glifosato, mancozeb, dimetoato y clorotalonil (García Hernández et al. 2017). En el bajío Guanajuatense, los PAPs más utilizados son clorpirifos, malatión, carbarilo y atrazina (PérezOlvera et al. 2017). En el Estado de México los PAPs más utilizados son: metomilo, metamidofos, monocrotofos y carbofurán (Castillo-Cadena et al. 2017). En los Altos de Chiapas, los floricultores utilizan principalmente el metamidofos, paratión metílico, carbofurán, mancozeb, paraquat y glifosato. Específicamente en cultivos de maíz se cita el uso de paraquat, 2,4-D, glifosato, paratión metílico, fosfuro de aluminio, monocrotofos y lambda cialotrina (Bernardino-Hernández et al. 2017). En la península de Yucatán, los más utilizados son el glifosato, paraquat, 2,4-D, imidacloprid, cipermetrina, clorpirifos, metamidofos, y endosulfán (Gómez-González 2017). Finalmente, en Campeche los más utilizados en cultivos de jitomate son el carbofurán, metamidofos, paratión metílico, metomilo, endosulfán y paraquat (Rendón-Von-Osten e Hinojosa-Garro 2017).

\section{Efectos en el ambiente}

Una gran parte de los agroquímicos que se aplican en los campos de cultivo, se movilizan a través del aire, suelo y agua hacia ecosistemas terrestres y acuáticos como ríos, lagos y zonas costeras (Arellano-Aguilar y Rendón von Osten 2017). Por lo tanto, estos ecosistemas pueden presentar residuos químicos y efectos en los organismos. A continuación se citan los estudios realizados en ecosistemas costeros, suelos y biota.

\section{Residuos en ecosistemas costeros}

En los últimos 20 años se han realizado estudios de monitoreo de residuos químicos en ecosistemas costeros del Pacífico Norte (Sonora, Sinaloa y Nayarit), Golfo de México y Pacífico Sur. Notablemente, la región que abarca los estados de Chiapas, Oaxaca, Guerrero, Michoacán y Colima ha sido poco estudiada en esta temática.

\section{Pacífico Norte}

Se han realizado alrededor de 20 estudios en la región del Pacífico Norte, en los que se reportan OC como los isómeros $\alpha, \beta, \gamma, \delta$, de $\mathrm{HCH}$, heptacloro, endosulfán, DDT y sus metabolitos (4,4'-DDD y 4,4'-DDE). También se ha detectado la presencia de OF como clorpirifos, diazinón y malatión; en muestras de agua, sedimento y organismos acuáticos en concentraciones máximas de $3.0 \mu \mathrm{g} / \mathrm{g}$ de peso seco (Cuadro I). Las mayores concentraciones de OC se reportan en el tejido blando de ostiones del Estero San Cristóbal en Nayarit (hasta $2.91 \mu \mathrm{g} / \mathrm{g}$ de $\delta-\mathrm{HCH}$, $1.43 \mu \mathrm{g} / \mathrm{g}$ de metoxicloro y 0.90 de endosulfán), en Bahía de Lobos, en Sonora (hasta $1.11 \mu \mathrm{g} / \mathrm{g}$ de endrín aldehído) (Osuna-López et al. 2014), en camarón silvestre de la Bahía de Ohuira, Topolobampo en Sinaloa $(2.0 \mu \mathrm{g} / \mathrm{g}$ de endosulfán I) (Osuna-Flores y Riva 2002) y en tejido comestible de jaiba café de esta misma bahía $(0.91 \mu \mathrm{g} / \mathrm{g}$ de endosulfán I) (GarcíaHernández et al. 2015). Respecto a los OF, BurgosHernández et al. (2006) detectaron hasta $2.85 \mu \mathrm{g} / \mathrm{g}$ de clorpirifos en sedimento de granjas acuícolas de Sonora y García-de la Parra et al. (2014) reportaron concentraciones de hasta $1.5 \mu \mathrm{g} / \mathrm{g}$ de diazinón en sedimento del cuerpo de agua de Ensenada del Pabellón en Sinaloa.

Concentraciones menores pero detectables de OC se han reportado en agua, sedimento y organismos acuáticos en ecosistemas del Pacífico Norte (Cuadro I). Por ejemplo, Robledo-Marenco et al. (2006) reportaron concentraciones de OC menores de $0.060 \mu \mathrm{g} / \mathrm{g}$ en sedimento y camarón de Bahía de San Blas, Nayarit. De forma similar, Vargas-González et al. (2016) 
CUADRO I. CONCENTRACIÓN DE PLAGUICIDAS OC, OF Y PS EN DIFERENTES MATRICES AMBIENTALES DE ECOSISTEMAS COSTEROS DE MÉXICO

\begin{tabular}{|c|c|c|c|c|}
\hline Fuente & Localidad & Matriz & Analito & $\begin{array}{l}\text { Concentración } \\
(\mu \mathrm{g} / \mathrm{g}) \text { peso seco }\end{array}$ \\
\hline \multirow{4}{*}{$\begin{array}{l}\text { Osuna-López } \\
\text { et al. } 2014\end{array}$} & \multirow{3}{*}{ Estero San Cristóbal, Nay. } & \multirow{3}{*}{$\begin{array}{l}\text { Crassostrea } \\
\text { corteziensis }\end{array}$} & $\delta-\mathrm{HCH}$ & 2.91 \\
\hline & & & metoxicloro & 1.43 \\
\hline & & & endosulfán II & 0.90 \\
\hline & Bahía de Lobos, Son. & & endrín aldehído & 1.11 \\
\hline \multirow{3}{*}{$\begin{array}{l}\text { Osuna-Flores y } \\
\text { Riva } 2002\end{array}$} & \multirow{3}{*}{ Bahía de Ohuira, Sin. } & agua & DDT & 0.0037 \\
\hline & & sedimento & $\delta-\mathrm{HCH}$ & 1.19 \\
\hline & & camarón silvestre & endosulfán I & 2.0 \\
\hline $\begin{array}{l}\text { García de la Parra } \\
\text { et al. } 2014\end{array}$ & Ensenada del Pabellón, Sin. & sedimento & diazinón & 1.5 \\
\hline \multirow{4}{*}{$\begin{array}{l}\text { García-Hernández } \\
\text { et al. } 2015\end{array}$} & Bahía de Ohuira, Sin. & \multirow{4}{*}{$\begin{array}{l}\text { Callinectes } \\
\text { bellicosus }\end{array}$} & endosulfán I & 0.913 \\
\hline & Laguna Agiabampo, Son. & & endosulfán I & 0.563 \\
\hline & Laguna Yavaros, Son. & & $\beta-\mathrm{HCH}$ & 0.316 \\
\hline & Bahía de Lobos, Son. & & heptacloro & 0.264 \\
\hline \multirow{2}{*}{$\begin{array}{l}\text { Robledo-Marenco } \\
\text { et al. } 2006\end{array}$} & \multirow{2}{*}{ San Blas, Nay. } & sedimento & 4,4'-DDT & 0.056 \\
\hline & & Litopenaeus spp. & $\beta-\mathrm{HCH}$ & 0.033 \\
\hline \multirow{3}{*}{$\begin{array}{l}\text { Vargas-González } \\
\text { et al. } 2016\end{array}$} & Yavaros, Son. & Chione californiensis & heptacloro & 0.073 \\
\hline & Altata, Sin & & heptacloro & 0.017 \\
\hline & Reforma, Sin. & & aldrín & 0.007 \\
\hline \multirow{5}{*}{$\begin{array}{l}\text { Burgos-Hernández et al. } \\
2006\end{array}$} & \multirow{5}{*}{ La Atanasia, Son. } & \multirow{3}{*}{$\begin{array}{l}\text { camarón de } \\
\text { granja }\end{array}$} & malatión & 0.035 \\
\hline & & & paratión & 0.012 \\
\hline & & & clorpirifos & 0.013 \\
\hline & & \multirow{2}{*}{$\begin{array}{l}\text { sedimento de } \\
\text { granja }\end{array}$} & clorpirifos & 2.85 \\
\hline & & & 4,4'-DDD & 2.15 \\
\hline \multirow{2}{*}{$\begin{array}{l}\text { Galindo-Reyes et al. } \\
1999\end{array}$} & \multirow{2}{*}{ Bahía Santa María, Sin. } & agua & dimetoato & 0.0005 \\
\hline & & sedimento & disulfoton & 0.018 \\
\hline Carvalho et al. 2002 & Ensenada del Pabellón, Sin. & sedimento & 4,4'-DDE & 0.026 \\
\hline \multirow{2}{*}{ González-Farias et al. 2002} & \multirow{2}{*}{ Agiabampo, Son. } & \multirow{2}{*}{ sedimento } & heptacloro & 0.064 \\
\hline & & & 4,4 '-DDT & 0.051 \\
\hline \multirow{2}{*}{$\begin{array}{l}\text { Granados-Galván et al. } \\
2015\end{array}$} & \multirow{2}{*}{ Navachiste-Macapule, Sin. } & \multirow{2}{*}{ Lutjanus spp. } & $\alpha$-clordano & 0.095 \\
\hline & & & $\gamma-\mathrm{HCH}$ & 0.087 \\
\hline \multirow{3}{*}{ Reyes-Montiel et al. 2013} & \multirow{3}{*}{ Navachiste-Macapule, Sin. } & \multirow{3}{*}{$\begin{array}{l}\text { Mugil } \\
\text { cephalus }\end{array}$} & $\alpha-\mathrm{HCH}$ & 0.295 \\
\hline & & & dieldrin & 0.356 \\
\hline & & & metoxicloro & 0.224 \\
\hline
\end{tabular}


CUADRO I. CONCENTRACIÓN DE PLAGUICIDAS OC, OF Y PS EN DIFERENTES MATRICES AMBIENTALES DE ECOSISTEMAS COSTEROS DE MÉXICO

\begin{tabular}{|c|c|c|c|c|}
\hline Fuente & Localidad & Matriz & Analito & $\begin{array}{l}\text { Concentración } \\
(\mu \mathrm{g} / \mathrm{g}) \text { peso seco }\end{array}$ \\
\hline \multirow{2}{*}{ Montes et al. 2012} & \multirow{2}{*}{ Navachiste-Macapule, Sin. } & \multirow{2}{*}{ sedimento } & $\beta-\mathrm{HCH}$ & 0.533 \\
\hline & & & $\delta-\mathrm{HCH}$ & 0.07 \\
\hline \multirow{2}{*}{ Galindo-Reyes et al. 1997} & \multirow{2}{*}{ Huizache-Caimanero, Sin. } & agua & lindano & 0.0026 \\
\hline & & sedimento & 4,4'-DDT & 0.022 \\
\hline \multirow{3}{*}{ Rosales y Escalona, 1983} & \multirow{2}{*}{ Yavaros, Son. } & \multirow{2}{*}{ Mugil cephalus } & endrin & 0.032 \\
\hline & & & dieldrin & 0.033 \\
\hline & Huizache-Caimanero, Sin. & Mugil cephalus & 4,4'-DDT & 0.051 \\
\hline \multirow{3}{*}{$\begin{array}{l}\text { García-Hernández et al. } \\
2013\end{array}$} & \multirow{3}{*}{ Delta del Río Colorado } & agua & $\sum \mathrm{HCH}$ & 0.0008 \\
\hline & & sedimento & $\sum \mathrm{HCH}$ & 0.024 \\
\hline & & peces & $\sum \mathrm{HCH}$ & 0.462 \\
\hline \multirow{2}{*}{ Lugo-Ibarra et al. 2011} & \multirow{2}{*}{ Delta del Río Colorado } & sedimento superficial & $\sum \mathrm{DDT}$ & 0.009 \\
\hline & & sedimento de núcleo & $\sum \mathrm{DDT}$ & 0.047 \\
\hline Macías-Zamora et al. 2014 & Costa Pacífico de Baja California & sedimento & $\sum \mathrm{DDT}$ & 0.003 \\
\hline \multirow{2}{*}{ González-Mille et al. 2010} & \multirow{2}{*}{ Río Coatzacoalcos desembocadura } & sedimento & $\alpha-\mathrm{HCH}$ & 0.643 \\
\hline & & Eugerres auxilliaris & $\beta-\mathrm{HCH}$ & 0.916 \\
\hline \multirow{2}{*}{ Gold-Bouchot et al. 2013} & \multirow{2}{*}{ Río Grijalva desembocadura } & \multirow{2}{*}{ hígado de Ariopsis felis } & $\sum$ drines & 0.404 \\
\hline & & & $\sum \mathrm{HCH}$ & 0.387 \\
\hline \multirow{3}{*}{ Botello et al. 2000} & \multirow{3}{*}{$\begin{array}{l}\text { Lagunas de Chantuto-Panzacola y } \\
\text { Carretas-Pereira }\end{array}$} & \multirow{3}{*}{ sedimento } & endosulfán II & 0.250 \\
\hline & & & heptacloro epóxido & 0.120 \\
\hline & & & aldrin & 0.160 \\
\hline \multirow{3}{*}{$\begin{array}{l}\text { Hernández-Romero et al. } \\
2004\end{array}$} & \multirow{3}{*}{ Laguna de Pozuelos-Murillo, Chis. } & agua & DDD & 0.002 \\
\hline & & \multirow{2}{*}{ sedimento } & Endosulfán I & 0.814 \\
\hline & & & DDE & 0.247 \\
\hline
\end{tabular}

reportaron concentraciones de OC menores de 0.070 $\mu \mathrm{g} / \mathrm{g}$ en almeja Chione californiensis de Yavaros, Altata y la Reforma. Otros estudios en Sinaloa, reportaron concentraciones menores de $0.018 \mu \mathrm{g} / \mathrm{g}$ de disulfoton en Bahía Santa María (Galindo-Reyes et al. 1999). En el delta del Río Colorado, se observaron valores en sedimento superficial de hasta 0.024 $\mu \mathrm{g} / \mathrm{g}$ de $\sum \mathrm{HCH}$ (García-Hernández et al. 2013) y en núcleos de sedimento se detectaron hasta $0.047 \mu \mathrm{g} / \mathrm{g}$ de $\sum$ DDT (Lugo-Ibarra et al. 2011). En este mismo ecosistema, se reportaron concentraciones de hasta $0.462 \mu \mathrm{g} / \mathrm{g}$ de $\sum \mathrm{HCH}$ en peces (García-Hernández et al. 2013). Por otro lado, Leyva-Morales et al. (2017b) en un monitoreo (julio 2008-junio 2009) de agua superficial del Río Culiacán al noroeste de México (Culiacán, Humaya y Tamazula) detectaron la presencia de OC [aldrín $(0.1023 \mathrm{mg} / \mathrm{L})$, DDT $(0.0425$ $\mathrm{mg} / \mathrm{L})$, endosulfán $(0.0198 \mathrm{mg} / \mathrm{L})$, heptacloro $(0.0059$ $\mathrm{mg} / \mathrm{L})$ y lindano $(0.0045 \mathrm{mg} / \mathrm{L})]$, OF [ (carbofenotión $(0.0099 \mathrm{mg} / \mathrm{L})$, clorpirifos $(0.0157 \mathrm{mg} / \mathrm{L})$, diazinón $(0.0403 \mathrm{mg} / \mathrm{L})$, etión $(0.0162 \mathrm{mg} / \mathrm{L})$ y paratión metílico $(0.0098 \mathrm{mg} / \mathrm{L})]$, PS [permetrina $(0.2351 \mathrm{mg} / \mathrm{L})]$, CA [carbarilo $(0.1113 \mathrm{mg} / \mathrm{L})$ y pirimicarb $(0.0722$ $\mathrm{mg} / \mathrm{L})$ ] y otros grupos químicos [ciromazina $(0.1961$ $\mathrm{mg} / \mathrm{L})$ ]; sin embargo, cabe mencionar que las concentraciones y frecuencias reportadas por los autores 
fueron relativamente bajas y ninguna superó la normativa mexicana ni la establecida por la Agencia de Protección Ambiental de Estados Unidos de América.

En relación a los efectos de los plaguicidas, se han realizado algunos estudios con organismos centinela. Por ejemplo, en ostiones (Crassostrea corteziensis) de estero Boca de Camichín, Nayarit se midió la actividad acetilcolinesterasa (AChE) como biomarcador de efecto, resultando en una disminución del $65 \%$ de su actividad en los ostiones colectados del estero respecto a los controles (Bernal-Hernández et al. 2010).

\section{Golfo de México}

En el Golfo de México González-Mille et al. (2010) reportaron concentraciones de $\alpha-\mathrm{HCH}(0.643$ $\mu \mathrm{g} / \mathrm{g})$ en sedimento y de $\beta$-HCH $(0.916 \mu \mathrm{g} / \mathrm{g})$ en mojarras de la desembocadura del Río Coatzacoalcos, Veracruz (Cuadro I), asimismo, detectaron daño al ADN en hemolinfa de peces omnívoros (Mugil cephalus y Oreochromis sp.) de este sitio a través del ensayo cometa. En el estado de Tabasco, GoldBouchot et al. (2013) observaron altos niveles de $\sum$ drines $(0.404 \mu \mathrm{g} / \mathrm{g})$ y $\sum \mathrm{HCH}(0.387 \mu \mathrm{g} / \mathrm{g})$ en hígado de bagres (Ariopsis felis) de la desembocadura del río Grijalva.

\section{Pacífico Sur}

En esta zona se detectaron OC en sedimento de las lagunas de Chantuto-Panzacola y Carretas-Pereira de la parte sur del estado de Chiapas, con concentraciones máximas de endosulfán II $(0.250 \mu \mathrm{g} / \mathrm{g})$, heptacloro epóxido $(0.120 \mu \mathrm{g} / \mathrm{g})$ y aldrín $(0.160 \mu \mathrm{g} / \mathrm{g})$ (Botello et al. 2000). También al sur del estado de Chiapas, Hernández-Romero et al. (2004) reportan en sedimento concentraciones de endosulfán I $(0.814$ $\mu \mathrm{g} / \mathrm{g})$ y de DDE $(0.2 \mu \mathrm{g} / \mathrm{g})$ de la laguna de PozuelosMurillo, Chiapas.

\section{Residuos en suelos}

Las mayores concentraciones de $\mathrm{OC}$ en suelos han sido reportadas por Martínez-Salinas et al. (2011) en suelo y polvo de comunidades de Chiapas en donde se utilizó el DDT para el control de la malaria de 1957 al 2000. En este estudio se detectaron concentraciones de DDT en suelo exterior de las viviendas de hasta $16.7 \mu \mathrm{g} / \mathrm{g}$ y en polvo interior de hasta $1551 \mu \mathrm{g} / \mathrm{g}$. Además, el cociente DDT/DDD+DDE, resultó en valores mayores a uno, lo que indica un uso reciente. Asimismo, Herrera-Portugal et al. (2005) realizaron muestreos en sangre de niños en comunidades donde se utilizó el DDT hasta el año 2000, mismas que al compararse con comunidades en donde se utilizó hasta 1980, presentaron concentraciones de DDT hasta ocho veces mayores $(37.5 \mu \mathrm{g} / \mathrm{L})$. Asimismo, en suelos exteriores a las viviendas, se presentaron concentraciones de DDT de hasta $9.9 \mu \mathrm{g} / \mathrm{g}$ y DDE de $21 \mu \mathrm{g} / \mathrm{g}$.

Estos valores son extremadamente altos y representan un riesgo potencial para los habitantes y ecosistemas de comunidades rurales de Chiapas.

Wong et al. (2008) realizaron un muestreo en suelo de comunidades de Chiapas, Veracruz y Tabasco reportando un uso más reciente de DDT en Chiapas y un uso pasado en muestras de suelo de Veracruz y Tabasco. De acuerdo con Alegría et al. (2006), las concentraciones de 4,4'-DDT y 4,4'-DDE en aire de Tapachula Chiapas $\left(808 \mathrm{pg} / \mathrm{m}^{3}\right)$ fueron mayores a las registradas en la región de los Grandes Lagos, en el Ártico y praderas de Canadá y en la parte sur de Estados Unidos, aunque los valores son similares a las concentraciones detectadas en Belice.

Resultados de residuos en suelos agrícolas del resto del país, reportan presencia de OC, principalmente DDTs, sin embargo, las concentraciones detectadas fueron menores a $0.2 \mu \mathrm{g} / \mathrm{g}$. Leal-Soto et al. (2013) reportaron la presencia de $17 \mathrm{OC}$ en suelos agrícolas de Sonora, con mayores concentraciones de DDE $(0.07$ $\mu \mathrm{g} / \mathrm{g}$ ) en el Valle de Guaymas. Waliszewski (2008) reportó la presencia de $\mathrm{OC}$ en suelos agrícolas de Puebla y Estado de México, con 4,4'-DDT a mayores concentraciones $(0.99 \mu \mathrm{g} / \mathrm{g})$. Velasco et al. (2014), realizaron análisis de suelos agrícolas del distrito de riego Río Verde en San Luis Potosí y detectaron 4,4'DDT con las mayores concentraciones $(0.14 \mu \mathrm{g} / \mathrm{g})$, también reportaron paratión metílico y etílico con concentraciones máximas de $0.05 \mu \mathrm{g} / \mathrm{g}$. García de la Parra et al. (2012) detectaron concentraciones de 4,4'-DDE de $0.02 \mu \mathrm{g} / \mathrm{g}$, y diazinón de $1.3 \mu \mathrm{g} / \mathrm{g}$, en sedimento de drenes agrícolas del Valle de $\mathrm{Cu}-$ liacán, Sinaloa. En sedimentos de drenes agrícolas de Tabasco, se detectaron concentraciones de 0.23 $\mu \mathrm{g} / \mathrm{g}$ de etilen-tiourea (ETU), metabolito principal del fungicida mancozeb que se utiliza en el cultivo del banano (Melgar et al. 2008). En suelos del Valle del Yaqui, se reportaron residuos de PS, con mayores concentraciones de cialotrina $(0.065 \mu \mathrm{g} / \mathrm{g})$ (Moreno-Villa et al. 2012). Mientras que, en el Valle de Maneadero en Baja California, se detectaron 22 compuestos en muestras de suelo, donde las mayores concentraciones fueron de endosulfán $(0.008 \mu \mathrm{g} / \mathrm{g})$ (Zúñiga-Violante et al. 2015). En el Valle de Culiacán Leyva-Morales et al. (2015) reportaron la presencia de OC [pp'-DDE $(0.06955 \mu \mathrm{g} / \mathrm{g})$, endosulfán a $(0.02039$ $\mu \mathrm{g} / \mathrm{g})$, endosulfán b $(0.02661 \mu \mathrm{g} / \mathrm{g})$, endosulfán sulfato $(0.04982 \mu \mathrm{g} / \mathrm{g})$ y lindano $(0.00135 \mu \mathrm{g} / \mathrm{g})]$, 
OF [clorpirifos $(0.01467 \mu \mathrm{g} / \mathrm{g})$, diazinón $(0.00014 \mu \mathrm{g} / \mathrm{g})$, dimetoato $(0.00271 \mu \mathrm{g} / \mathrm{g})$, malatión $(0.07394 \mu \mathrm{g} / \mathrm{g})$ y paratión metílico $(0.00113 \mu \mathrm{g} / \mathrm{g})]$, PS [bifentrín $(0.00228 \mu \mathrm{g} / \mathrm{g})$, cipermetrina $(0.02264 \mu \mathrm{g} / \mathrm{g})$, esfenvalerato $(0.00214 \mu \mathrm{g} / \mathrm{g})]$ y compuestos de uso reciente [clorotalonil $(0.14621 \mu \mathrm{g} / \mathrm{g})$, boscalid $(0.03426 \mu \mathrm{g} / \mathrm{g})$, thiametoxam $(0.00421 \mu \mathrm{g} / \mathrm{g})$ y azoxystrobin $(0.00998 \mu \mathrm{g} / \mathrm{g})]$; donde, la concentración de lindano sobrepasó, en algunas zonas muestreadas, los niveles de acción establecidos en la Guía de Calidad del Suelo de Canadá para la Protección del Ambiente y la Salud Humana.

Los resultados de los estudios en suelo, indican una degradación gradual de OC en zonas agrícolas, sin embargo, se demuestra su persistencia al estar todavía presentes en la mayoría de los sitios muestreados. Por otro lado, los valores de DDT encontrados en suelos de comunidades rurales de Chiapas representan una preocupación, al estar hasta 8,000 veces por encima de lo registrado para suelos agrícolas del resto del país, lo que indica una urgente necesidad de realizar programas de monitoreo y medidas efectivas para la protección de estas comunidades.

\section{Residuos en fauna silvestre}

Estudios en mamíferos marinos del Noroeste de México, indican la presencia principalmente de $\sum$ DDT en tejido adiposo de ballenas, delfines y lobos marinos. No se cuenta con información reciente para el resto de las zonas costeras mexicanas, sobre todo en el Pacífico Sur, donde hay evidencia de uso reciente de DDT (Herrera-Portugal et al. 2005). Gallo-Reynoso et al. (2014) reportaron concentraciones medias de $\sum$ DDT de $15.43 \mu \mathrm{g} / \mathrm{g}$ y máximas de $87.3 \mu \mathrm{g} / \mathrm{g}$ en tejido adiposo de delfín de rostro largo (Delphinus capensis) de la región central del Golfo de California, las concentraciones medias de $\sum$ DDT estuvieron por debajo de lo reportado en especies similares del Mediterráneo (157 $\mu \mathrm{g} / \mathrm{g}$ ) (Borrell y Aguilar 2005) y mayores a las del Océano Atlántico $(9.51 \mu \mathrm{g} / \mathrm{g})($ Borrell et al. 2001) colectados en fechas similares. Niño-Torres et al. (2009) reportaron concentraciones medias de $\sum$ DDT de $1.2 \mu \mathrm{g} / \mathrm{g}$ y máximas de $2.4 \mu \mathrm{g} / \mathrm{g}$ en tejido adiposo de ballena de aleta (Balaenoptera physalus) de la región central del Golfo de California; la concentración media de $\sum$ DDT estuvo por debajo de lo reportado para el Mediterráneo $(5.7 \mu \mathrm{g} / \mathrm{g})$ (Marsili y Focardi 1997) y para el Atlántico noroeste $(26.9 \mu \mathrm{g} / \mathrm{g}$ ) (Hobbs et al. 2003). Del Toro et al. (2006) colectaron muestras de tejido adiposo de lobos marinos de California (Zalophus californianus californianus) varados en la Bahía de Todos Santos, Baja California. La concentración media de DDE fue de $3.3 \mu \mathrm{g} / \mathrm{g}$ y la máxima de $7.82 \mu \mathrm{g} / \mathrm{g}$. Estas concentraciones de DDE estuvieron por debajo de las reportadas para esta especie recolectada en Oregon Estados Unidos $(8.1 \mu \mathrm{g} / \mathrm{g}$ ) (Hayteas y Duffield 1997).

En lo que respecta a reptiles, Cobos-Gasca et al. (2011) realizaron muestreos de huevos de tortuga carey (Eretmochelys imbricata) la cual es una especie protegida de acuerdo a la Norma Oficial Mexicana NOM-059-SEMARNAT-2010 (SEMARNAT 2010). Los muestreos se realizaron de huevos no eclosionados de siete campamentos tortugueros de la costa de Campeche. Sus resultados indicaron concentraciones medias de DDT de hasta $2.1 \mu \mathrm{g} / \mathrm{g}$ y de $\mathrm{DDE}$ de $13.8 \mu \mathrm{g} / \mathrm{g}$ en peso húmedo, detectándose las mayores concentraciones cerca a la desembocadura del río Champotón lo cual pudiera indicar una fuente de estos contaminantes de acuerdo a los autores. Asimismo, García-Besné et al. (2015) colectaron muestras de sangre y huevos de tortugas carey y verde (Chelonia mydas) durante su anidación en las costas de Campeche. Los resultados indican concentraciones máximas (base lipídica) de metoxicloro en sangre de tortuga verde $(0.045$ $\mu \mathrm{g} / \mathrm{g})$ y 4,4 '-DDD $(0.042 \mu \mathrm{g} / \mathrm{g})$ en tortuga carey. En muestras de huevos, las mayores concentraciones fueron de endrín cetona $(1.2 \mu \mathrm{g} / \mathrm{g})$ en tortuga verde y de 4,4'-DDD $(4.7 \mu \mathrm{g} / \mathrm{g})$ en tortuga carey. Los autores mencionan que estas concentraciones, con excepción del 4,4'-DDE, están por encima de lo reportado para tortugas caguamas (Caretta caretta) y tortugas lora (Lepidochelys kempii) de Carolina del Norte, Estados Unidos (Keller et al. 2004 a, b). García-Solorio et al. (2014) realizaron una recolecta de huevos no viables de tortuga golfina (Lepidochelys olivacea) de playa Ceuta, Sinaloa. Las concentraciones (base húmeda) máximas reportadas fueron de $\beta-\mathrm{HCH}(6.44 \mu \mathrm{g} / \mathrm{g})$, $\gamma-\mathrm{HCH}(4.39 \mu \mathrm{g} / \mathrm{g})$ y endosulfán $(4.48 \mu \mathrm{g} / \mathrm{g})$. Debido a que encontraron diferencias entre nidos pero no entre diferentes grados de desarrollo del embrión, los autores concluyen que los plaguicidas detectados provienen de la madre y no son adquiridos durante su permanencia en el nido. Gardner et al. (2003) realizaron muestreos de diferentes tejidos (hígado, riñón, tejido adiposo y músculo) de tortugas que murieron durante la actividad pesquera cercana a Bahía Magdalena y La Paz, en Baja California Sur. Las mayores concentraciones de OC se detectaron en tejido adiposo de tortuga prieta (Chelonia mydas agassizzii) $\left(0.065 \mu \mathrm{g} / \mathrm{g}\right.$ base húmeda de $\sum$ clordanos $)$, de acuerdo a los autores, estudios similares realizados en tortugas verdes de Hawaii reportaron niveles no detectables de clordanos (Aguirre et al. 1994). 
González-Jaúregui et al. (2012) muestrearon sangre de cocodrilo Mexicano (Crocodylus moreletti) en el río Champotón y la reserva Los Petenes, Campeche. Sus resultados muestran concentraciones en plasma (base lipídica) máximas de dieldrín $(0.90 \mu \mathrm{g} / \mathrm{g})$ en muestras de la reserva Los Petenes. Los autores mencionan que detectaron $\sum \mathrm{HCH}$ en muestras silvestres mientras que en muestras de cultivo no se detectaron estos compuestos.

Respecto a anfibios, se tiene información del estado de Veracruz, Península de Yucatán y Sinaloa, sin embargo, es necesario ampliar los estudios en vida silvestre, incluyendo los estados del sur del país debido a las concentraciones elevadas de OC detectadas en suelos (Herrera-Portugal et al. 2005). Valdespino et al. (2015) realizaron colectas de anfibios (ranas de las especies Charadrahyla taeniopus y Ecnomiohyla miotympanum) en Veracruz (Xalapa y Xico), sus resultados indican concentraciones (base lipídica) muy elevadas de $\sum \mathrm{HCH}(4,746 \mu \mathrm{g} / \mathrm{g})$, de $\sum$ DDT $(2,637 \mu \mathrm{g} / \mathrm{g})$, de heptacloro $(1,400 \mu \mathrm{g} / \mathrm{g})$, de endosulfán $(1,600 \mu \mathrm{g} / \mathrm{g})$, de metoxicloro $(900 \mu \mathrm{g} / \mathrm{g})$ de drines $(800 \mu \mathrm{g} / \mathrm{g})$ y de clordanos $(300 \mu \mathrm{g} / \mathrm{g})$. Estos resultados coinciden con otros estudios en los que reportan concentraciones altas de OC en anfibios, comparados con otros niveles tróficos de la cadena alimenticia (Goutner et al. 2012). Sin embargo, las concentraciones de $\sum$ DDT detectadas en anfibios de Veracruz estuvieron muy por encima de las reportadas para anfibios colectados en otras partes del mundo, como China (0.01 - $1 \mu \mathrm{g} / \mathrm{g})$ (Teng et al. 2013).

En aves marinas y terrestres, la investigación se ha orientado hacia la determinación de residuos en sangre, huevos, plumas o cuerpo completo. La mayor parte de estos estudios se ubican en las zonas costeras del Pacífico Norte. En este sentido, Mellink et al. (2009) detectaron DDE $(0.053 \mu \mathrm{g} / \mathrm{g}$ base húmeda) en huevos de bobos cafés (Sula leucogaster) de las islas San Jorge y San Pedro Mártir en Sonora. En la isla Peña Blanca, Colima, se detectaron concentraciones menores a $0.01 \mu \mathrm{g} / \mathrm{g}$ y de acuerdo a los autores, el grosor del cascarón no se vio afectado por las concentraciones de DDE. Jiménez-Castro et al. (1995) colectaron huevos de gaviota occidental (Larus occidentalis) en la costa del Pacífico Norte e identificaron concentraciones de DDE en San Martín (12.6 $\mu \mathrm{g} / \mathrm{g}$ base húmeda), en Todos Santos $(12.3 \mu \mathrm{g} / \mathrm{g})$ e islas Coronados $(12.2 \mu \mathrm{g} / \mathrm{g})$, los autores no reportaron adelgazamiento del cascarón debido a las concentraciones de DDE y mencionan una disminución de las concentraciones en relación a estudios anteriores en la zona. Por otro lado, RiveraRodríguez y Rodríguez-Estrella (2011) reportaron concentraciones máximas de $0.007 \mu \mathrm{g} / \mathrm{L}$ de endrín cetona y $0.004 \mu \mathrm{g} / \mathrm{L}$ de DDE en muestras de sangre de pollo de águila pescadora (Pandion haliaetus) de Laguna San Ignacio, Baja California Sur. En aves terrestres, González-Escalante et al. (2013) determinaron la actividad AChE en sangre de gorriones domésticos (Passer domesticus) y pinzón mexicano (Carpodacus mexicanus) y observaron una mayor actividad de $\mathrm{AChE}$ en sangre de gorriones domésticos colectados en sitios no agrícolas $(1.39 \mathrm{U} / \mathrm{mL})$ comparados con los gorriones de los sitios agrícolas $(0.99 \mathrm{U} / \mathrm{mL})$ de Galeana, Monterrey. Estos datos son consistentes con los encontrados por Rendón-Von Osten et al. (2005) quienes observaron una menor actividad AChE (26.5 U/mg de proteína) en cerebro de pato pijije (Dendrocygna autumnalis) expuestos predominantemente a carbofurán, con respecto a aves no expuestas $(36.9 \mathrm{U} / \mathrm{mg}$ de proteína) y aves control (40 U/mg de proteína) colectados en el Río Palizada, Campeche. Asimismo, Cobos et al. (2006) reportaron hasta un $49.4 \%$ de inhibición de actividad AChE en el zorzal pardo (Turdus grayi) capturados en plantaciones de papaya recién fumigadas con 1.5 $\mathrm{kg} /$ ha de diazinón en la península de Yucatán. GarcíaHernández et al. (2006) reportan concentraciones con valores máximos de $0.06 \mu \mathrm{g} / \mathrm{g}$ peso húmedo de $\gamma$-HCH y DDT en huevos de paloma huilota (Zenaida macroura) y concentraciones de hasta $0.04 \mu \mathrm{g} / \mathrm{g}$ de DDE y DDT en tecolote llanero (Athene cunicularia) del delta del Río Colorado. Por su parte, Mora y Anderson (1991) reportaron DDE $(13.4 \mu \mathrm{g} / \mathrm{g}$ peso húmedo) en cuerpo completo de cormoranes (Phalacrocorax auritus) del Valle de Culiacán, mientras que en zanate (Quiscalus mexicanus) reportaron hasta $9.4 \mu \mathrm{g} / \mathrm{g}$ en el Valle de Mexicali y hasta de $4.4 \mu \mathrm{g} / \mathrm{g}$ de DDE en el Valle del Yaqui. Los autores discuten posibles riesgos en el Valle de Mexicali debido a la acumulación de DDE y $\sum \mathrm{HCH}$ en palomas (Zenaida macroura) y tordos de ala roja (Agelaius phoniceus), ya que forman parte de la dieta del halcón peregrino (Falco peregrinus), una especie enlistada en la NOM059-SEMARNAT-2010 (SEMARNAT 2010). De hecho, Mora et al. (2011) reportaron la presencia de DDE en huevos de halcón aplomado (Falco femoralis septentrionalis) colectados en áreas de anidación de Chihuahua ( $7.85 \mu \mathrm{g} / \mathrm{g}$ base lipídica) y Veracruz $(5.51 \mu \mathrm{g} / \mathrm{g})$, aunque el grosor del cascarón no mostró signos de adelgazamiento debido al DDE. Por otro lado, aves paseriformes residentes colectadas en zonas adyacentes al lago de Chapala en Michoacán (Mora 2008), mostraron concentraciones máximas de DDE de hasta $12 \mu \mathrm{g} / \mathrm{g}$, mientras que aves migratorias presentaron concentraciones de DDE de hasta 
$0.01 \mu \mathrm{g} / \mathrm{g}$. Este estudio indicó una posible fuente local (drenaje pluvial) de plaguicidas. El tecolote bajeño (Glaucidium brasilianum) fue muestreado por Arrona-Rivera et al. (2016) en zonas adyacentes a la reserva Cerro Sonsonate en Chiapas, los autores detectaron hasta $2.0 \mu \mathrm{g} / \mathrm{g}$ de $\sum \mathrm{HCH}$ y hasta $1.86 \mu \mathrm{g} / \mathrm{g}$ de $\sum$ endosulfán en plumas, así como $1.77 \mu \mathrm{g} / \mathrm{L}$ de $\sum$ drines y $0.23 \mu \mathrm{g} / \mathrm{L}$ de $\sum \mathrm{DDTs}$ en sangre. Los autores reportaron que las concentraciones detectadas fueron mayores a las reportadas por Rivera-Rodríguez y Rodríguez-Estrella (2011) en muestras de sangre de águila pescadora (Pandion haeliaetus) en Laguna San Ignacio, Baja California Sur.

En relación a concentraciones de residuos de plaguicidas en insectos, Valdovinos-Flores et al. (2016) evaluaron la presencia de cumafós en panales de abejas de Yucatán. Este es un OF lipofílico y persistente que se utiliza contra el SHB (pequeños escarabajos abejeros). El cumafós estuvo presente en $100 \%$ de las muestras de cera a concentraciones entre 0.155 y $2.22 \mu \mathrm{g} / \mathrm{g}$ y en $64 \%$ de muestras de miel a concentraciones entre 0.005 y $0.040 \mu \mathrm{g} / \mathrm{g}$. Sin embargo, este plaguicida no está autorizado en México para uso en panales de abejas (CICOPLAFEST 2016). Las concentraciones detectadas en miel, no excedieron los límites establecidos para Estados Unidos y la Unión Europea. En cuanto a la cera, se ha establecido un valor de toxicidad $\mathrm{LC}_{50}$ para Apis mellifera de $46 \mathrm{mg} / \mathrm{L}$ pero en estadio larvario este valor se reduce a $8 \mathrm{mg} / \mathrm{L}$ y a concentraciones menores pudieran manifestarse efectos sub-letales como anormalidades en larvas, alteraciones en el comportamiento y menor peso de las abejas reinas (Valdovinos-Flores et al. 2016).

\section{Estudios ecotoxicológicos}

Hasta ahora se han presentado resultados de monitoreo ambiental realizados en diferentes organismos y regiones de México. Sin embargo, existen más de 60 artículos derivados de investigaciones ecotoxicológicas recientes realizadas en México en peces (i.e. Martínez-Tabche et al. 1994, Dzul-Caamal et al. 2012, Díaz-Resendiz et al. 2015, Sánchez-Garayzar et al. 2016, Toledo-Ibarra et al. 2016), reptiles (Aguilera-González et al. 2015), anfibios (RoblesMendoza et al. 2009), crustáceos (i.e. Galindo-Reyes et al. 2002, Comoglio et al. 2005, Roque et al. 2005, Betancourt et al. 2006, García de la Parra et al. 2006), rotíferos (i.e. Gama-Flores et al. 1999, Sarma et al. 2001, Pérez-Legaspi et al. 2010, Arias-Almeida y Rico-Martínez 2011, Alvarado-Flores et al. 2015), bivalvos (Anguiano et al. 2007, 2010) e insectos (Valdovinos-Núñez et al. 2009, Pérez-Cogollo et al.
2015). Dichos estudios relacionan exposición de OC, OF, CA, PS y herbicidas, con efectos en la salud de organismos de prueba.

\section{Exposición en población humana}

En las secciones anteriores se ha presentado una revisión sobre la presencia de residuos, principalmente $\mathrm{OC}$ en ecosistemas costeros, suelos, mamíferos marinos, reptiles, anfibios, aves e insectos de las zonas costeras del país con influencia agrícola, en la que es evidente que la mayoría de los compuestos utilizados son considerados peligrosos para el ambiente. En las siguientes secciones se abordarán los efectos que tiene el uso de estos compuestos, principalmente $\mathrm{OF}$, en la salud de la población expuesta.

\section{Exposición en trabajadores agrícolas}

A continuación, se describen diversos estudios realizados en poblaciones mexicanas que han evidenciado los efectos causados por exposición a OF, CA, PS y OC. En un estudio realizado por Recio et al. (2005) con trabajadores agrícolas de Villa Juárez Durango, en donde se cultivan hortalizas y se aplicó principalmente paratión metílico, metamidofos, endosulfán, dimetoato y diazinón, se encontró una asociación negativa entre la presencia de algunos metabolitos de plaguicidas y los niveles circulantes en sangre de la hormona folículo estimulante (FSH) y la hormona luteinizante, ambas responsables del control endócrino. Resultados similares se observaron en floricultores del Estado de México expuestos a OF, en los cuales se observó un incremento de la hormona FSH y prolactina, así como una disminución de niveles de testosterona e inhibina B en suero (Aguilar-Garduño et al. 2013). También en Villa Juárez, Durango, trabajadores agrícolas mostraron una asociación significativa entre la concentración de OF y un incremento en el número anormal de cromosomas en espermatozoides (aneuploides), lo que sugiere que la exposición a OF puede interferir con la segregación cromosómica en estas células germinales e incrementar el riesgo de síndromes genéticos como el síndrome de Turner (Recio et al. 2001). Asimismo, estudios en la comunidad de Muna, Yucatán, muestran que un $88 \%$ de los agricultores expuestos a OF, OC, CA, PS (i.e. metamidofos, clorpirifos etil, malatión, diazinón, endosulfán, dicofol, permetrina, carbarilo) presentaron daño al ADN y una relación significativa entre la exposición a OF y la disminución en algunos parámetros de calidad de semen como la morfología, motilidad y viabilidad espermática (Pérez-Herrera et al. 2008). 
Trabajadores agrícolas del Valle de Mexicali y San Quintín, Baja California donde se utilizan una gran variedad de compuestos con características carcinogénicas, teratógenas y genotóxicas (i.e. azinfós metílico, oxidemeton metil, acefate, trifluralina, diclorvos, endosulfán, paratión metílico, malatión, paraquat, entre otros), presentaron efectos genotóxicos en muestras de sangre. Estos efectos estuvieron determinados por una mayor frecuencia de micronúcleos, brotes nucleares y puentes de cromatina en comparación con aquellos miembros de las mismas comunidades no relacionadas directamente con actividades agrícolas (Zúñiga-Violante et al. 2012, Arellano-García et al. 2013). Trabajadores agrícolas de la zona de tierra caliente de Guerrero expuestos a endosulfán, paratión metílico, azinfós metílico, metamidofos, aldicarb, cipermetrina, dicamba, entre otros, presentaron daño genético en muestras de exudados bucales, expresado como mayor migración de la cola de ADN y mayor frecuencia de micronúcleos, además de presentar anomalías como células binucleadas, cromatina condensada, protuberancia nuclear, picnosis (núcleos encogidos), cariorrhexis (núcleos desintegrados) y cariolisis (núcleos disueltos); asociadas con efectos citotóxicos o genotóxicos (Carbajal-López et al. 2016). Resultados similares fueron reportados por Martínez-Valenzuela et al. (2009), quienes evaluaron intercambio de cromátidas hermanas en linfocitos de sangre periférica y micronúcleos y otras anomalías en exudados bucales de trabajadores agrícolas de Ahome, Sinaloa ocupacionalmente expuestos (malatión, paratión metílico, azinfos metílico, diazinón, monocrotofos, aldicarb, carbarilo, carbosulfan entre otros). Los autores reportaron una mayor frecuencia de micronúcleos $(2.83$ $\%$ ) en la población expuesta que en población no expuesta de la ciudad de Los Mochis (0.37\%), así como una mayor frecuencia de anomalías nucleares como células binucleadas, cromatina condensada, cariolisis, picnosis y cariorrhexis en trabajadores expuestos. Por otro lado, Chaín-Castro et al. (1998) reportaron que un $20 \%$ de los jornaleros de campos agrícolas de Culiacán, Sinaloa, reportan haberse intoxicado al menos una vez por el uso de plaguicidas durante su vida laboral, principalmente los encargados de las mezclas de agroquímicos. Otro estudio realizado en trabajadores agrícolas en Sinaloa, reporta concentraciones promedio de colinesterasa eritrocítica (método de campo Magnotti) de $4.22 \mathrm{U} / \mathrm{mL} \pm 0.77$ observando que los niveles de esta enzima fueron más altos en hombres que en mujeres (Palacios-Nava et al. 2009).

Dentro de los trabajadores agrícolas, los y las trabajadoras del cultivo de la flor, también se han identificado como un grupo de alta exposición, debido a que esta actividad se lleva a cabo dentro de invernaderos y a que la aplicación de agroquímicos es constante durante todo el año. Blanco-Muñoz et al. (2016) observaron una relación positiva entre las concentraciones de DDE en suero y los niveles de hormonas tiroideas en floricultores de Morelos y Estado de México. También observaron una alteración del perfil hormonal de floricultores del sexo masculino expuestos a OF (Blanco-Muñoz et al. 2010). En floricultores de Morelos expuestos, se detectó daño significativo celular en linfocitos y células de exfoliado bucal (Gómez-Arroyo et al. 2000). Blanco-Muñoz et al. (2013) reportaron que existe una relación entre el polimorfismo genético materno de la PON1 (proteína involucrada en la detoxificación de OF) y la ocurrencia de abortos en mujeres floricultoras. Castillo-Cadena et al. (2006) realizaron muestreo de sangre de floricultores expuestos crónicamente, de la comunidad de Santa María Aransazú, Estado de México, utilizando una parte de la muestra para el ensayo cometa y otra para análisis de residuos. Se observó una mayor fragmentación del ADN en individuos expuestos comparados con los no expuestos, además se reportó la presencia de residuos de OF, CA, PS, ditiocarbamatos, tiocarbamatos, compuestos clorados, aditivos y solventes, en muestras de suero del $50 \%$ de los floricultores expuestos. En un estudio con floricultores de Villa Guerrero, Estado de México, Martínez-Luna et al. (2014) se evaluó la calidad del semen de trabajadores expuestos a metomilo, carbofurán, metamidofos y monocrotofos. Los autores reportaron una reducción significativa en el conteo de espermatozoides, menor motilidad y mayor frecuencia de anormalidades en muestras de semen de floricultores expuestos, comparado con una población no expuesta.

\section{Exposición en mujeres en edad reproductiva}

Entre los estudios realizados en mujeres en edad reproductiva, se encontraron los realizados en comunidades rurales de Chiapas, en mujeres expuestas a DDT a través del uso de este compuesto para el control del paludismo. Koepke et al. 2004 reportaron concentraciones de DDT y DDE en suero sanguíneo de mujeres embarazadas de Tapachula, Chiapas con variaciones de 0.05 a $23.1 \mu \mathrm{g} / \mathrm{g}$ y de $0.11 \mathrm{a} 41.9 \mu \mathrm{g} / \mathrm{g}$, respectivamente. Madres embarazadas residentes de Veracruz presentaron concentraciones de DDE y DDT en suero sanguíneo en niveles que variaron desde concentraciones por debajo del límite de detección del método a $0.98 \mu \mathrm{g} / \mathrm{g}$ y de 0.24 a 20.85 $\mu \mathrm{g} / \mathrm{g}$, respectivamente (Waliszewski et al. 2000). 
Rodríguez-Dozal et al. (2012) cuantificaron el DDE en plasma sanguíneo de madres que habitaban zonas urbanas del país (Querétaro, Tultitlán, Mérida, Salamanca, Monterrey, Guadalajara, Hermosillo, Córdoba, Coatzacoalcos y Cd. Obregón). Los autores encontraron que las habitantes de Coatzacoalcos tenían las mayores concentraciones de $\operatorname{DDE}(0.2 \mathrm{a}$ $4.3 \mu \mathrm{g} / \mathrm{g})$, seguido de las habitantes de Córdoba (0.09 a $2.1 \mu \mathrm{g} / \mathrm{g})$, Veracruz y Cd. Obregón, Sonora (0.87 a $19.7 \mu \mathrm{g} / \mathrm{g}$ ), aunque en este último sitio se presentó un valor extremo mayor al de las demás localidades. Las concentraciones de $\mathrm{OC}$ en leche materna, presentaron mayor variabilidad, con concentraciones altas detectadas en zonas rurales de Chiapas, Morelos y Veracruz. Los estudios se describen a continuación. Torres-Arreola et al. (1999) reportaron una concentración media (base lipídica) de $0.162 \mu \mathrm{g} / \mathrm{g}$ de 4,4'-DDT y $0.59 \mu \mathrm{g} / \mathrm{g}$ de 4,4 '-DDE y máxima de $7.91 \mu \mathrm{g} / \mathrm{g}$ de 4,4 '-DDE en leche materna de madres de la Ciudad de México. La edad materna, tiempo de lactancia, historia de haber vivido en una zona agrícola y consumo de carne y pescado salado fueron variables determinantes de la presencia de DDT en este estudio. Se estimó que el $6 \%$ de los infantes alimentados con leche materna excedieron el límite de la FAO de $0.005 \mu \mathrm{g} / \mathrm{g}$ de ingesta diaria de DDT. López-Guzmán et al. (2006) reportaron concentraciones de DDE (base lipídica) en leche materna de cuatro comunidades de Chiapas (El Ramonal, La Cigüeña, Faja de Oro y Tapachula) con valores medios de 1.2 y valores máximos de $15.8 \mu \mathrm{g} / \mathrm{g}$, en la comunidad El Ramonal, también reportaron concentraciones medias de DDE de la Huasteca en San Luis Potosí de $0.4 \mu \mathrm{g} / \mathrm{g}$ y máximos de $2.7 \mu \mathrm{g} / \mathrm{g}$; de acuerdo a los autores, las concentraciones promedio de todas las comunidades (incluyendo Tapachula) excedieron la ingesta diaria de DDE aceptable de acuerdo a la OMS de $0.02 \mu \mathrm{g} / \mathrm{g}$ en leche materna. Chávez-Almazán et al. (2014) encontraron concentraciones de DDE en leche de madres de Guerrero de $0.89 \mu \mathrm{g} / \mathrm{g}$ con valores máximos de $5.6 \mu \mathrm{g} / \mathrm{g}$. Waliszewski et al. (2002) observaron concentraciones de $3.24 \mu \mathrm{g} / \mathrm{g}$ de DDE en leche de madres de veracruzanas, mientras que en leche materna de madres de Chelem, Yucatán, se detectó una concentración de $3.0 \mu \mathrm{g} / \mathrm{g}$ de DDE (Rodas-Ortíz et al. 2008).

En relación a los efectos causados por la presencia y exposición de plaguicidas en mujeres, se ha identificado una relación entre madurez placentaria y la exposición a OF, lo que puede afectar el transporte de nutrientes de la madre al feto (Acosta-Maldonado et al. 2009). Madres de niños con criptorquidia (testículos no descendidos) presentaron mayores concentraciones de DDT y $\beta$-HCH en suero, comparado con madres de niños con testículos descendidos (Bustamante-Montes et al. 2010). Lacasaña et al. (2006) reportaron que madres y padres trabajadores agrícolas presentaron un riesgo mayor de tener hijos con anencefalia. También se reportó que la exposición a DDE puede incrementar el riesgo de cáncer de mama, especialmente en mujeres postmenopáusicas (Romieu et al. 2000) y el riesgo de tumores benignos (Waliszewski et al. 2005). En estudios con mujeres en edad reproductiva expuestas a DDT y sus metabolitos, se ha reportado daño genético medido a través del ensayo cometa en muestras de sangre (Yáñez et al. 2004). Guillette et al. (2006) reportaron un mayor crecimiento de senos, así como una baja relación entre el desarrollo de la glándula mamaria y tamaño del seno en jóvenes de zonas agrícolas del Valle del Yaqui, Sonora, comparadas con jóvenes de zonas serranas con menor exposición. Además, se encontró una asociación significativa entre la exposición a plaguicidas medido a través de la actividad $\mathrm{AChE}$ $(<20 \%)$ y un retraso en el crecimiento intrauterino (Levario-Carrillo et al. 2004).

\section{Exposición en niños}

Los niños son posiblemente el grupo más vulnerable a la exposición y efectos de los plaguicidas, debido a su masa corporal menor y a que tienen un mayor contacto boca-mano con su entorno (Gamlin et al. 2006). Martínez-Salinas et al. (2004) reportaron concentraciones altas de DDT (concentración media de $0.15 \mu \mathrm{g} / \mathrm{g}$ y máxima de $11.8 \mu \mathrm{g} / \mathrm{g}$ ) y DDE (concentración media de $21.1 \mu \mathrm{g} / \mathrm{g}$ y máxima de 194.4 $\mu \mathrm{g} / \mathrm{g}$ ) en muestras de sangre de niños de comunidades rurales de Chiapas. Dentro de los efectos que se han reportado en niños, se encuentran el deterioro en el desarrollo neuronal temprano (Torres-Sánchez et al. 2013) y la reducción significativa del índice de orientación espacial de niños expuestos a DDE de zonas palúdicas en Chiapas (Osorio-Valencia et al. 2015). En niños del Valle del Yaqui en Sonora, se observó una disminución en energía, en coordinación ojo-mano fina y gruesa, en memoria de 30 minutos y en la habilidad de dibujar una persona (Guillette et al. 1998). Así mismo, se observó una posible relación entre 3,5,6-tricloro-2-piridinol (un biomarcador de exposición de clorpirifos y clorpirifos-metil) con el trastorno de déficit de atención, en niños de la ciudad de México (Fortenberry et al. 2014). La exposición a mezclas de contaminantes (DDT y PAHs) producen mayores daños al ADN en niños expuestos, comparado con exposición a un solo contaminante (Jasso-Pineda et al. 2015). En este sentido, niños 
ocupacionalmente expuestos a OF y CA en plantaciones de tabaco de Nayarit, presentaron una disminución de la actividad AChE entre $15 \mathrm{y}$ hasta $19 \%$ (Gamlin et al. 2006). También se ha detectado un mayor porcentaje de apoptosis (0.1 a $16.20 \%)$ medido con el ensayo TUNEL en células sanguíneas mononucleares de niños expuestos a DDE de Oaxaca (Ventanilla), Chiapas (La Cigüeña) y Quintana Roo (El Ramonal), con mayores porcentajes en esta última comunidad y menores en Oaxaca (Pérez-Maldonado et al. 2006).

\section{Exposición en comunidades indígenas}

Otro grupo vulnerable, son los pueblos nativos o comunidades indígenas de México ya que cada año miles de mujeres, hombres, niños y niñas son transportados desde sus comunidades de origen a los grandes campos agroindustriales del centro y norte del país, así como a los Estados Unidos. De Oaxaca y Guerrero salen la mitad de los jornaleros agrícolas. De Oaxaca la mayoría son mixtecos, trikis y zapotecos; de Guerrero son tlapanecos y nahuas, así como grupos indígenas de Michoacán, Hidalgo, Veracruz y Yucatán. Además de los indígenas huicholes, coras y tepehuanos que trabajan en los campos tabacaleros de Nayarit (Díaz-Romo y Salinas-Álvarez, 2002). Con el objetivo de evaluar los efectos de los plaguicidas OF y CA en la salud de los trabajadores agrícolas de la zona tabacalera del norte de Nayarit, Díaz-Romo y Salinas-Álvarez (2002), realizaron un estudio epidemiológico de corte transversal con seguimiento en 1995-1997. La población del estudio estuvo integrada por jornaleros indígenas principalmente huicholes, jornaleros mestizos y ejidatarios. Los resultados indicaron un nivel medio de $\mathrm{AChE}$ durante la cosecha del tabaco fue de $28.27 \mathrm{U} / \mathrm{g} \mathrm{Hb}$ (unidades internacionales por gramo, corregidas por hemoglobina), lo cual fue significativamente menor que el nivel basal de $30.39 \mathrm{U} / \mathrm{g} \mathrm{Hb}$. Dentro del grupo expuesto, los jornaleros indígenas presentaron los mayores niveles de inhibición de AChE durante la cosecha respecto a niveles basales. En este contexto, Bernal-Hernández et al. (2014) encontraron actividades más bajas de las enzimas butirilcolinesterasa (BuChE) y PON1 así como alteraciones hematológicas en jornaleros indígenas huicholes que con respecto a una población indígena control.

En los valles agrícolas de Baja California (San Quintín, Maneadero y Mexicali), Camarena-Ojinaga et al. (2013) realizaron entrevistas a 50 mujeres indígenas jornaleras agrícolas. Las entrevistas indicaron que las mujeres están en constante exposición a 32 i.a. entre los que destacan por su toxicidad paraquat, malatión, metomilo y diazinón. También reportaron efectos por contacto indirecto como irritaciones, comezón, ronchas y manchas en la piel, así como cefaleas y vómito en algunos casos. Se concluyó que las trabajadoras agrícolas indígenas se encuentran en condiciones precarias por la falta de información sobre los riesgos de los plaguicidas, falta de equipo de protección adecuados y a que no cuentan con seguridad social (IMSS o seguro popular), lo que hace a este grupo particularmente vulnerable ante los riesgos a la salud derivados de la exposición a estos compuestos.

Exposición en expendedores y aplicadores urbanos

Otro grupo identificado como vulnerable, son los expendedores de productos agrícolas y los aplicadores de insecticidas en medio urbano. Rojas-García et al. (2011) reportaron una disminución significativa en la actividad de BuChE y parámetros sanguíneos como contenido de hemoglobina y hematocrito, en expendedores de agroquímicos comparados con una población control de Nayarit. Por su parte, AldanaMadrid et al. (2003) reportaron diferencias significativas en la calidad del líquido seminal (disminuida viabilidad y concentración) entre aplicadores urbanos y un grupo control. Asimismo, un estudio realizado por Zepeda-Arce et al. (2016) encontró un mayor daño genético en fumigadores urbanos expuestos principalmente a OF y PS, con respecto a un grupo de referencia, así como un papel importante de la actividad de enzimas antioxidantes en la modulación de este efecto.

\section{Residuos en alimentos}

Una de las matrices más analizadas es la leche de vaca, diferentes estudios indican presencia de OF de manera general y de OC en leche de Chiapas y Veracruz, los cuales se describen a continuación.

En leche de vaca de granjas de Veracruz, se detectaron concentraciones de $\beta$-HCH $(0.09 \mu \mathrm{g} / \mathrm{g})$, DDT $(0.04 \mu \mathrm{g} / \mathrm{g})$ y DDE $(0.03 \mu \mathrm{g} / \mathrm{g})$, con una disminución de los valores de 1998 a 2001 debido probablemente a la sustitución en 1999 del DDT por PS para el control del paludismo (Waliszewski et al. 2003). También, se detectaron residuos de OC en leche de vaca de productores industriales de Hidalgo donde la concentración varió entre $<\mathrm{LD}$ (límite de detección) a $0.0009 \mu \mathrm{g} / \mathrm{g}$ y los isómeros de $\mathrm{HCH}$ (hasta 0.0007 $\mu \mathrm{g} / \mathrm{g}$ ) y endosulfán sulfato (hasta $0.0009 \mu \mathrm{g} / \mathrm{g}$ ) presentaron las mayores concentraciones. Los autores mencionan que estas concentraciones no excedieron las normativas del Codex Alimentarius (Gutiérrez et al. 2013). De acuerdo con Schettino et al. (2013), las 
concentraciones de $\mathrm{OC}$ en leche de cabra de granjas del centro del país, no representan un riesgo para los consumidores. En un estudio realizado por Salas et al. (2003) con leche de vaca comercial, se identificó que cerca del $40 \%$ de las muestras presentaron residuos de OF y $8 \%$ presentaron concentraciones mayores a los límites máximos permitidos, principalmente diclorvos.

En granjas de ovejas de Veracruz se detectaron niveles altos de OC en carne. Las concentraciones encontradas representan un riesgo carcinogénico potencial por el consumo de este alimento (Pardío et al. 2012). Aldana-Madrid et al. (2008a) detectaron residuos de malatión (hasta $0.025 \mu \mathrm{g} / \mathrm{g}$ en frijol), clorpirifos (hasta $0.0058 \mu \mathrm{g} / \mathrm{g}$ en trigo), deltametrina (hasta $0.114 \mu \mathrm{g} / \mathrm{g}$ en frijol y chícharo), cipermetrina (hasta $0.367 \mu \mathrm{g} / \mathrm{g}$ en chícharo) y metabolitos del DDT (hasta $0.019 \mu \mathrm{g} / \mathrm{g}$ en maíz) en granos de almacenes de Sonora; las concentraciones de cipermetrina fueron las únicas que estuvieron por encima del límite máximo de residuos. En muestras de nopal fresco se detectó malatión en $97 \%$ de las muestras, con concentraciones por debajo del límite máximo de residuos y se detectó clorpirifos $(0.002 \mu \mathrm{g} / \mathrm{g})$ y paratión metílico $(0.056 \mu \mathrm{g} / \mathrm{g})$, ambos no autorizados para hortalizas (Aldana-Madrid et al. 2008b). En muestras de hortalizas colectadas en mercados de Sonora, se detectaron $9 \%$ de las muestras con residuos de piretroides $(0.004$ a $0.57 \mu \mathrm{g} / \mathrm{g})$, con mayores concentraciones de ciflutrín en cebolla $(0.57 \mu \mathrm{g} / \mathrm{g})$, sin embargo, no se reportó riesgo a la salud por consumo de estos productos (Aldana-Madrid et al. 2011). Por otro lado, análisis de tejido adiposo en res, puerco y aves, de plantas procesadoras localizadas al norte del país, resultaron en concentraciones por debajo del nivel de detección para OP en el caso de carne de puerco tampoco se detectaron residuos de OC, mientras que en carne de res se detectaron residuos de hexaclorobenceno (HCB) $(0.30 \mu \mathrm{g} / \mathrm{g})$, heptacloro $(0.20 \mu \mathrm{g} / \mathrm{g})$, aldrín $(0.26 \mu \mathrm{g} / \mathrm{g})$ y dieldrín $(0.23 \mu \mathrm{g} / \mathrm{g})$. En muestras de aves de corral para consumo humano se encontraron HCB $(0.28 \mu \mathrm{g} / \mathrm{g})$, heptacloro $(0.10$ $\mu \mathrm{g} / \mathrm{g})$ y dieldrín $(0.04 \mu \mathrm{g} / \mathrm{g})$, por lo que de acuerdo a los autores, las concentraciones detectadas fueron menores a las de otros sitios en México y Latinoamérica, pero mayores a los reportados para Estados Unidos. Ninguna de las concentraciones excedió los límites máximos de residuos (Vázquez-Moreno et al. 1999).

\section{Toxicología de plaguicidas (estudios in vitro e in vivo)}

Los estudios realizados en sistemas in vivo e in vitro representan una herramienta útil para conocer los efectos y los mecanismos de toxicidad de los plaguicidas sobre los sistemas celulares, efectos fisiológicos y en el comportamiento de los organismos (Eaton y Gilbert 2013). En este sentido, se tienen avances importantes en la investigación a través de sistemas in vitro e in vivo en México.

En el caso de los OF, Arteaga-Gómez et al. (2016) emplearon células cutáneas (queratinocitos) y células bronquiales como modelo de cultivo para evaluar los efectos de azinfos metílico, paratión metílico, ometoato y metamidofos. La viabilidad, así como daño genotóxico evaluado por medio del ensayo cometa presentaron una disminución en las células tratadas. Estudios en células sanguíneas humanas periféricas mononucleares tratadas con paratión metílico y con metabolitos de alquilfosfatos (dietilfosfato, dietiltiofosfato, dietilditiofosfato, dimetilfosfato y dimetilditiofosfato) por 48 horas, mostraron que los tratamientos con paratión metílico no produjeron toxicidad directa de las células a las concentraciones evaluadas (de 0 a $1500 \mu \mathrm{M}$ ), sin embargo, el dimetil fosfato y el dimetil ditiofosfato, mostraron toxicidad significativa a 50 y $500 \mu \mathrm{M}$, respecto al control (Lima y Vega 2005). También en células sanguíneas humanas periféricas mononucleares, Castillo-Sosa et al. (2009) observaron que a concentraciones de diazinón entre 5 y $50 \mu \mathrm{M}$, disminuyó el número de células viables o se estimuló su proliferación sobre el control, los autores también reportan apoptosis y necrosis celular pero solo con diazinón comercial no con diazinón grado analítico, por lo que los efectos necróticos se pudieran atribuir a los compuestos no activos del plaguicida. Por su parte Cortés-Eslava et al. (2013) realizaron un ensayo de co-incubación de células/microorganismos para evaluar el efecto de cuatro OF (paratión metílico, azinfos metílico, ometoato y metamidofos) metabolizados por una planta (cilantro, Coriandrum sativum). Todos los OF mostraron un decremento en la toxicidad de células humanas cuando se cultivaron en presencia del metabolismo de la planta $C$. sativum, aunque indujeron mutaciones en las cepas bacterianas. Esquivel-Sentiés et al. (2010) realizaron exposición de dietilditiofosfato (un metabolito de OF) en células de linfocitos $\mathrm{T}$, este compuesto causa la modulación de la fosforilación de proteínas intracelulares, lo que puede resultar en que las células $T$ fracasen en su respuesta antígena alterando la función inmune del organismo ocasionando enfermedades como inmunosupresión, hipersensibilidad y enfermedades autoinmunes. Medina-Díaz et al. (2011) evaluaron el efecto de clorpirifos y paratión metílico en células de hepatocarcinoma humano (HepG2), los resultados indicaron 
que la exposición a estos compuestos incrementó el nivel de glutatión S-transferesa (GSTA) relativo al control, lo cual podría resultar en falla terapéutica o modulación de la toxicidad por endobióticos y xenobióticos que son metabolizados por GSTA. También en este tipo de células (HepG2) expuestas a paratión metílico y clorpirifos, disminuyeron el mRNA de PON1 y se observó un incremento de las citoquinas inflamatorias. Estas respuestas indican una mayor susceptibilidad a intoxicación por OF y el riesgo de enfermedades relacionadas con inflamación y estrés oxidativo (Medina-Díaz et al. 2017). Bonilla et al. (2008) trataron ovocitos de ratón con los malatión y diazinón, se observando una reducción significativa $(52 \%)$ en la sobrevivencia de los ovocitos después de 24 horas de exposición, además se observaron alteraciones en la expresión de genes que codifican proteínas de procesos celulares esenciales (una regulación decreciente del citocromo oxidasa subunidad III, subunidad I y de la proteína ribosomal S16 y regulación creciente de la proteína $\mathrm{BP} 75)$. Por otro lado, se ha observado daño genético primario (por medio del ensayo cometa) en células periféricas sanguíneas humanas, en respuesta a exposición a etil paraoxon (metabolito de paratión etílico), con mayor efecto en células de recién nacidos (Islas-González et al. 2005). Albores et al. (2001) observaron una alta actividad inhibitoria de $\mathrm{AChE}$ por paratión metílico en extractos de cerebro de rata, así como un efecto protector de la sustancia fenobarbital sódico en contra de la inhibición de AChE por paratión metílico. Así mismo, estudios in vitro sugieren la capacidad de temefos de causar daño genotóxico estable, un OF utilizado como larvicida de elección para el control A. aegypti, en células HePG2 (Benítez-Trinidad et al. 2015).

También la exposición a paratión metílico en ratones, se asoció a una disminución de la capacidad de fertilización, derivada de efectos en la integridad del ADN espermático (Piña-Guzmán et al. 2009).

Por otro lado, Romero-Navarro et al. (2006) evaluaron el efecto del diclorvos en la actividad glucoquinasa hepática y pancreática, expresión génica y en los niveles de insulina mRNA de ratas Wistar expuestas. Sus resultados mostraron que el plaguicida disminuye la actividad de la glucoquinasa en el hígado, lo que puede resultar en efectos adversos en el metabolismo de la glucosa por este plaguicida. Segura et al. (1999) evaluaron los mecanismos de toxicidad aguda del sistema respiratorio inducidos por paratión en conejos. Sus resultados mostraron que las alteraciones respiratorias se producen por una combinación de factores (contracción de los músculos lisos de las vías respiratorias, incremento de secreciones mucosas y edema pulmonar) además dosis subclínicas de paratión, causaron hiperrespuesta de las vías aéreas, siendo los conejos hembras más sensibles que los machos, y la exposición repetida causó tolerancia, aunque no previno el desarrollo de toxicidad de las vías respiratorias a nivel funcional. Experimentos en ratas Wistar expuestas a cadmio y paratión, indicaron que la presencia simultánea de estos compuestos disminuyó la letalidad ligeramente, sin embargo, se observó un efecto hepatotóxico en los organismos expuestos (Meléndez-Camargo y LópezHernández 1998). En ratones adultos expuestos a metamidofos se observó una inhibición de AChE y un incremento en células anormales (UriósteguiAcosta et al. 2014). En ratas tratadas con una mezcla de paratión metílico y permetrina, se observó un incremento en la toxicidad aguda (LD50) comparada con la exposición a un solo ingrediente activo (Ortíz et al. 1995). Levario-Carrillo et al. (2004) reportaron que ratas expuestas a paratión metílico presentaron alteraciones en células placentarias. Por su parte, Castillo et al. (2002) reportaron que la coexposición a endosulfán y paratión metílico en ratas, ocasionó mayores latencias de escape, mayores números de fallas para llegar a la plataforma, y más tiempo en la periferia del tanque, en la prueba del laberinto acuático, comparado con exposición a un solo plaguicida o al control, lo que indica alteraciones conductuales por la exposición a esta mezcla de compuestos.

Respecto a los OC, también se reportan estudios in vitro e in vivo en diferentes modelos de experimentación. Pérez-Maldonado et al. (2004) identificaron un nivel de apoptosis celular significativo, inducido por DDT, DDD y DDE en células sanguíneas humanas periféricas mononucleares. Estos resultados fueron validados en muestras sanguíneas de niños, resultando mayores niveles de apoptosis en individuos con mayores concentraciones. Alegría-Torres et al. (2009) expusieron células sanguíneas humanas periféricas mononucleares a DDE, lo que causó respuesta antioxidante e inducción de biomarcadores inflamatorios. Domínguez-López et al. (2012) observaron que células humanas derivadas de trofoblastos expuestas a DDD y DDE indujeron la expresión de la proteína COX-2 que incrementó la producción de prostaglandina E2, la cual interviene en respuesta inflamatoria, controlan el descenso de la presión arterial, entre otras funciones importantes. Por otro lado, Nuñez et al. (2002) observaron que la exposición de DDT grado técnico a un cultivo de macrófagos, resultó en la inhibición de la función del macrófago y redujo la habilidad de limitar el crecimiento intracelular de 
la bacteria Mycobacterium leprae, lo que indica que la exposición a este plaguicida puede representar un riesgo para el desarrollo de infecciones. En caso de los OC heptacloro y heptacloro epóxido, Prado et al. (2009) expusieron células humanas linfoblastoides resultando en que ambos compuestos indujeron daños en ADN, medidos con el ensayo cometa (biomarcador de daño primario), aunque no ocasionaron un incremento en la formación de micronúcleos (biomarcador de daño permanente). Oropeza-Hernández et al. (2001) expusieron a ratas Wistar hembras a lindano, resultando en un incremento de la expresión del citocromo $\mathrm{P} 450$ hepático en relación a la concentración del plaguicida, este efecto fue mayor en hembras con ovariectomía que en hembras control, posiblemente porque no existe una fuente de estrógeno para contrarrestar los efectos del lindano.

También se han realizado estudios in vitro con PS. Ramos-Chávez et al. (2015) realizaron exposición de células sanguíneas humanas periféricas a permetrina y aletrina, mostrando un incremento en la frecuencia de micronúcleos, porcentaje de células apoptóticas y tejido necrótico. Vences-Mejía et al. (2012) evaluaron el efecto de transflutrin y D-aletrina en ratas "Wistar" expuestas a estos por inhalación (utilizando redes de mosquitero repelentes). Sus resultados indicaron la inducción de citocromo P450 (CYP2E1 y CYP3A2) en cerebro y cerebelo, pero no en microsomas de hígado, por lo que los autores concluyen que estos plaguicidas pudieran incrementar el riesgo de neurotoxicidad. También se ha realizado exposición in vivo de cipermetrina, Aldana et al. (2001) utilizaron ratas "Wistar" expuestas a concentraciones subletales de cipermetrina. Sus resultados indicaron signos típicos de intoxicación en los organismos (salivación, columna vertebral encorvada, comezón, ataxia, convulsiones e hipersensibilidad), disminución del peso corporal e incremento del peso del hígado; además se detectaron alteraciones en las funciones hepáticas (disminución de albúmina en suero), cambios en el perfil lipídico (i.e. disminución de colesterol y triglicéridos en suero) y daños en el tejido hepático (i.e. incremento de mitocondria, inflamación del retículo endoplásmico) sin embargo, los autores observaron que los signos de intoxicación y toxicidad disminuyeron significativamente en organismos tratados con $\alpha$-tocoferol. Vargas-Medrano et al. (2011) evaluaron el efecto de cipermetrina, deltametrina y glifosato sobre la actividad enzimática de la $\mathrm{Ca}^{2+}$-ATPasa de membrana plasmática y de retículo sarcoplásmico, mostrando que la actividad enzimática de la membrana fue parcialmente inhibida por deltametrina, $\mathrm{y}$ estimulada por deltametrina y glifosato, sugiriendo alteraciones de la regulación celular del calcio en los organismos. En cuanto al herbicida glifosato, Hernández-Plata et al. (2015) mostraron que ratas "Sprague-Dowley" expuestas a este compuesto vía inyecciones intraperitoneales, presentaron hipoactividad acompañada por una disminución en uniones específicas a receptores de dopamina (D1-DA) en el cerebro (núcleo accumbens), lo que confirma que este herbicida afecta el comportamiento motor y el sistema dopaminérgico en organismos.

\section{Bioplaguicidas y biorremediación}

El campo de investigación de los bioplaguicidas y bioremediación ha tenido avances importantes en los últimos años en México. Por ejemplo, Thompson et al. (2000) e Infante-Rodríguez (2011) investigaron la efectividad del larvicida de origen natural spinosad, derivado de dos moléculas producidas durante la fermentación de un actinomiceto del suelo. En zonas de acumulación de agua donde se produce la larva del mosquito, el spinosad mostró una efectividad similar al OF temefos (Garza-Robledo et al. 2011, Marina et al. 2014). Asimismo, se documentó su efectividad contra la larva de la mosca negra (Simulium spp.), la cual es un vector de la oncocercosis (Infante-Rodríguez et al. 2011), y en contra de un lepidóptero (Spodeptera littoralis) plaga del algodón (Pineda et al. 2004).

Con respecto a la biorremediación, se ha investigado la degradación de OC. Islas-García et al. (2015) identificaron la presencia de hongos y bacterias, que toleran concentraciones de hasta $20 \mu \mathrm{g} / \mathrm{g}$ de OC, lo que indica la posibilidad de bioremediación de suelos contaminados usando bioestimulación de estos microorganismos nativos. Seyhi et al. (2013) utilizaron gavilla de trigo para preparar un filtro de carbón activado para la adsorción de heptacloro. Del mismo modo se ha investigado la remoción de metil paratión en diferentes medios. Al respecto, se utilizaron bacterias (E. coli DH5 $\alpha$ ) inmovilizadas en tezontle para la degradación de paratión metílico en efluentes (Abdel-Razek et al. 2013) y también se ha documentado la disminución de este contaminante utilizando plantas acuáticas (Typha latifolia) (Amaya-Chávez et al. 2006) y organismos bentónicos (Dugesia dorotocephala) (Amaya-Chávez et al. 2009). También se probó la eficiencia de la reacción de Fenton -que consiste en un proceso de oxidación avanzado con peróxido de hidrógeno- en la remoción de clorotalonil sólo y en presencia de paratión metílico y metamidofos. El porcentaje de eficiencia de remoción de los tres plaguicidas fue del $98 \%$ y el tiempo de degradación máximo fue de $90 \mathrm{~min}$ para metamidofos (Gutiérrez et al. 2007). Asimismo, 
Aceves-Diez et al. (2015) emplearon al microorganismo Bacillus thuringiensis (derivadas del sobrenadante del proceso de fermentación) como agente bioestimulante para mejorar y sostener poblaciones que asistan en el proceso de biorremediación de suelos contaminados con clorpirifos. Sus resultados indicaron una mayor degradabilidad de clorpirifos ( $83 \%$ ) y su producto metabólico 3,5,6-tricloro-2-piridinol (TCP) (30\%), en suelos suplementados con B. thuringiensis. En el caso de atrazina, Guillén-Garcés et al. (2007) caracterizaron la mineralización microbiana en suelos y líquidos en presencia de fertilizante nitrogenado, sus resultados mostraron que únicamente un $20 \%$ de atrazina se mineralizó después de 18 días en presencia de nitrógeno, mientras que más del $90 \%$ de mineralización ocurrió después de un día, sin la presencia de nitrógeno.

\section{Recursos humanos}

El desarrollo de una línea base del estado actual de la investigación de plaguicidas en México, es una necesidad de la Red Temática de Toxicología de Plaguicidas. La Red se formó en 2015 con apoyo del Consejo Nacional de Ciencia y Tecnología (CONACyT) y tiene como objetivo principal conformar grupos multidisciplinarios con el fin de generar y desarrollar proyectos interdisciplinarios, así como, optimizar el uso de infraestructura que permitan dar soluciones a problemas relacionados con la temática en México (http://www.redtoxicologiadeplaguicidas.org/). Para esto la Red cuenta con una línea base obtenida de publicaciones arbitradas e indizadas, sobre el uso de estos compuestos a nivel nacional y sus efectos de éstos en diferentes modelos y niveles de organización celular. Lo anterior permite identificar las zonas en riesgo, así como, las posibles interacciones con investigadores que han contribuido en la temática para generar futuros proyectos interdisciplinarios que den solución al problema de los plaguicidas en México.

Como parte de esta revisión, se presenta un listado de universidades, centros de investigación e instituciones, que trabajan con esta temática en México (Cuadro II). Sin embargo, la lista está incompleta, por lo que hacemos un llamado a los lectores interesados a que se unan a la red y contribuyan con sus conocimientos.

\section{CONCLUSIONES}

De acuerdo a la revisión bibliográfica realizada se obtuvo un mayor porcentaje de publicaciones en el tema de exposición (32\%), seguido de efectos en el ambiente $(20 \%)$, estudios toxicológicos in vitro e in vivo (14\%), estudios ecotoxicológicos (13\%), bioplaguicidas y biorremediación $(13 \%)$, residuos en alimentos $(6 \%)$ y finalmente patrón y uso de plaguicidas $(2 \%)$. En cuanto al tema de patrón de uso de plaguicidas, se concluye que se están utilizando PAPs en zonas agrícolas del norte, centro y sur del país, en el caso de Sonora y Sinaloa, se cuantificó que entre un 40 y $50 \%$ son PAPs. Los ingredientes activos utilizados para diversos cultivos en el país, que destacan por su alta toxicidad son: paratión metílico, malatión, metamidofos, clorpirifos, monocrotofos, paraquat, glifosato, carbofurán, metomilo, mancozeb, clorotalonil, dimetoato, carbarilo, atrazina, 2,4-D, fosfuro de aluminio, imidacloprid, cipermetrina, lambda cialotrina y endosulfán.

En estudios de residuos en ecosistemas costeros, se destaca la presencia de OC en el estero San Cristóbal (Nayarit), en Topolobampo (Sinaloa), en bahía de Lobos (Sonora), en la bahía de Chetumal (Quintana Roo), en la desembocadura del Río Coatzacoalcos (Veracruz), y en las lagunas de Chantuto-Panzacola, Carretas-Pereira y Pozuelos-Murillo (Chiapas). En suelos destacan las altas concentraciones de OC en comunidades rurales de Chiapas debido a las campañas históricas contra el paludismo.

En mamíferos marinos (delfines, ballenas y lobos marinos), huevos de aves marinas del Pacífico Norte, huevos de tortugas de Sinaloa y anfibios del estado de Veracruz, se destaca la presencia de OC a concentraciones altas. También se reporta un estudio en donde se detectaron residuos de cumafós en cera y miel de abejas de Yucatán.

Respecto a la exposición en población humana, se han estudiado los efectos en trabajadores agrícolas, mujeres en edad reproductiva, niños, pueblos nativos, floricultores, expendedores y aplicadores urbanos expuestos a OF, CA, PS y OC. Los efectos más comunes encontrados en trabajadores agrícolas en general, son alteraciones genéticas (i.e. daño al ADN, mayor frecuencia de micronúcleos, brotes nucleares, puentes de cromatina, células binucleadas, cromatina condensada, protuberancia nuclear, núcleos desintegrados o disueltos), disminución en la calidad del semen (i.e. morfología, motilidad y viabilidad espermática). En mujeres, alteración del perfil hormonal, mayor incidencia de abortos, efecto en madurez placentaria, bebés con criptorquidia, mayor riesgo de anencefalia, incremento en el riesgo de cáncer de mama, mayor crecimiento de senos, retraso en el crecimiento intrauterino. En niños, deterioro en el desarrollo neuronal temprano, reducción significativa del índice de orientación espacial, disminución de energía, disminución de la coordinación ojo-mano 
CUADRO II. CENTROS DE INVESTIGACIÓN, UNIVERSIDADES E INSTITUCIONES QUE TRABAJAN CON TEMAS RELACIONADOS A PLAGUICIDAS EN MÉXICO

ESTADO INSTITUCIÓN

Morelos Instituto Nacional de Salud Pública. Centro de investigación en Salud Poblacional. Dirección de Salud Ambiental.

Universidad Nacional Autónoma de México (UNAM). Centro Regional de Investigaciones Multidisciplinarias. Instituto de Biotecnología (IBT).

Universidad de Sonora. Departamento de Investigación y Posgrado en Alimentos.

Universidad Autónoma del Estado de Morelos. Facultad de Farmacia. Centro de Investigación en Biotecnología (CEIB).

Instituto Mexicano de Tecnología del Agua Jiutepec Morelos.

Estado de Universidad Autónoma del Estado de México. Facultad de Química. Centro de Investigación en Ciencias Médicas México (CICMED).

Departamento de Biología Instituto Nacional de Investigaciones Nucleares

Instituto de Salud del Estado de México

Centro Estratégico Vigilancia Epidemiológica

Universidad Autónoma Chapingo. Plaguicidas y Malezas. Instituto de Horticultura. Fitopatología. Entomología. Parasitología Agrícola

Colegio de Posgraduados Campus Montecillo

Guerrero Universidad Autónoma de Guerrero. Unidad Académica de Ciencias Químico Biológicas. Unidad Académica de Ciencias Naturales. Unidad Académica de Microbiología

Ciudad de Centro de Investigación y de Estudios Avanzados del Instituto Politécnico Nacional (CINVESTAV-IPN).

México Departamento de Toxicología.

Universidad Nacional Autónoma de México (UNAM). Ciencias de la Atmósfera. Instituto de Investigaciones Biomédicas. Facultad de Ciencias. Facultad de Química. FES Iztacala. Instituto de Ciencias del Mar y Limnología

Universidad Autónoma Metropolitana (UAM)

Instituto Nacional de Cardiología

Instituto Nacional de Ecología

Instituto Nacional de Pediatría

Instituto Politécnico Nacional (IPN). Escuela Nacional de Ciencias Biológicas

Instituto Nacional de Ecología y Cambio Climático (INECC).

\begin{tabular}{|c|c|}
\hline Hidalgo & Universidad autónoma del Estado de Hidalgo \\
\hline Puebla & Benemérita Universidad Autónoma de Puebla \\
\hline \multirow[t]{2}{*}{ Tlaxcala } & Instituto Tecnológico del Altiplano de Tlaxcala \\
\hline & Universidad Autónoma de Tlaxcala. Facultad de Agrobiología, Centro de Investigación en Genética y Ambiente. \\
\hline \multirow[t]{5}{*}{ Campeche } & Universidad Autónoma de Campeche \\
\hline & Universidad del Mar, Campus Puerto Ángel \\
\hline & Instituto EPOMEX \\
\hline & Universidad Autónoma del Carmen \\
\hline & nstituto Tecnológico de Campeche \\
\hline
\end{tabular}




\begin{tabular}{|c|c|}
\hline ESTADO & INSTITUCIÓN \\
\hline \multirow[t]{2}{*}{ Chiapas } & ECOSUR \\
\hline & Instituto Tecnológico de Chetumal \\
\hline \multirow{2}{*}{$\begin{array}{l}\text { Quintana } \\
\text { Roo }\end{array}$} & ECOSUR \\
\hline & Instituto Tecnológico de Chetumal \\
\hline Tabasco & Universidad Juárez Autónoma de Tabasco División Académica de Ciencias Biológicas \\
\hline \multirow[t]{2}{*}{ Veracruz } & Universidad Veracruzana \\
\hline & Instituto Tecnológico de Veracruz \\
\hline \multirow[t]{2}{*}{ Yucatán } & Universidad Autónoma de Yucatán (UADY) \\
\hline & Centro de Investigación y Estudios Regionales Dr. Hideyo Noguchi. Unidad Biomédica. \\
\hline \multirow[t]{4}{*}{ Sinaloa } & Centro de Investigación en Alimentación y Desarrollo A.C. (Unidades Culiacán y Mazatlán) \\
\hline & Instituto Tecnológico de Culiacán \\
\hline & Universidad de Occidente \\
\hline & $\begin{array}{l}\text { Instituto Nacional de Investigaciones Forestales, Agrícolas y Pecuarias (INIFAP) campo experimental valle de } \\
\text { Culiacán y valle del Carrizo. }\end{array}$ \\
\hline
\end{tabular}

\begin{tabular}{|c|c|}
\hline \multirow[t]{3}{*}{ Sonora } & Centro de Investigación en Alimentación y Desarrollo A.C. (Unidades Guaymas y Hermosillo). \\
\hline & Universidad de Sonora. Departamento de Investigación y Posgrado en Alimentos. \\
\hline & Instituto Tecnológico de Sonora \\
\hline \multirow[t]{2}{*}{ Chihuahua } & Universidad Autónoma de Chihuahua \\
\hline & Centro de Investigación en Alimentación y Desarrollo A.C. (Unidad Delicias) \\
\hline $\begin{array}{l}\text { Baja } \\
\text { California } \\
\text { Sur }\end{array}$ & Centro de Investigaciones Biológicas del Noroeste (CIBNOR), Unidad La Paz \\
\hline Nayarit & Universidad Autónoma de Nayarit (UAN) \\
\hline $\begin{array}{l}\text { Baja } \\
\text { California } \\
\text { Norte }\end{array}$ & Universidad Autónoma de Baja California(UABC) \\
\hline \multirow[t]{2}{*}{ Jalisco } & Centro Universitario de Ciencias Biológicas y Agropecuarias (CUCBA) \\
\hline & Centro de Investigación y Asistencia en Tecnología y Diseño del Estado de Jalisco, A.C. (CIATEJ) \\
\hline Colima & Universidad de Colima \\
\hline
\end{tabular}

Nuevo León Centro de Investigación y Asistencia en Tecnología y Diseño del Estado de Jalisco, A.C. (CIATEJ) 
fina y gruesa, memoria de 30 minutos y habilidad para dibujar una persona, así como incremento en el déficit de atención, disminución en la AChE y mayor porcentaje de apoptosis.

En alimentos, como leche, se reportan residuos de OF, un $8 \%$ en concentraciones mayores a los límites permitidos, principalmente diclorvos. En trigo se presentan residuos de OF y OC, además con concentraciones de cipermetrina superiores a los límites máximos.

Se han realizado estudios in vitro e in vivo que demuestran la toxicidad de OF, CA, OC y PS a nivel celular y de organismo. En el caso de los OF, se reporta daño genético primario, apoptosis, necrosis celular, inhibición de AChE, alteración del sistema inmune, disminución de la enzima PON1, alteraciones en células placentarias, efectos en la glucoquinasa pancreática y hepática e incremento en resistencia pulmonar, toxicidad en hígado, entre otras y en organismos modelo, se observaron alteraciones del conductuales. En OC, se observaron apoptosis significativa, inducción de biomarcadores inflamatorios y daños al ADN. Y en PS también mostraron daño genético (micronúcleos, porcentaje de células apoptóticas y tejido necrótico), neurotoxicidad, intoxicación en organismos, cambios en el perfil lipídico y daños en tejido hepático.

En relación al tema de bioplaguicidas y biorremediación, el estudio de compuestos de origen natural, como spinosad, indica eficiencias similares a los tradicionales como temefos para el combate del mosquito, la mosca negra y lepidópteros. Se proponen diferentes mecanismos de bioremediación de suelos y aguas contaminadas, utilizando biofiltros, bioestimulación de suelos, reacción de Fenton entre otras.

Con base en lo anterior, se puede concluir que existe suficiente evidencia para determinar que el uso de plaguicidas, tanto histórico como actual, está asociado a al deterioro de los ecosistemas y la salud de la población de México. Es muy importante reconocer el esfuerzo que está haciendo la comunidad académica para estudiar y reportar los efectos en los organismos y el ambiente. Sin embargo, no podemos dejar de insistir en que las instancias gubernamentales son las responsables de dar a conocer a la población, la información cualitativa y cuantitativa precisa sobre el uso de plaguicidas por distrito de riego y zona palúdica del país. Sin esta información, no es posible estimar de manera integral la dimensión del problema, ni localizar zonas o poblaciones de riesgo, para establecer acciones de prevención y control de daños a la salud. Estamos seguros de que la comunidad académica, así como la Red Temática de Toxicología de Plaguicidas, están en la mejor disposición de apoyar cualquier iniciativa gubernamental orientada al monitoreo del uso y efecto de los plaguicidas en México.

\section{AGRADECIMIENTOS}

Los autores agradecen el apoyo de la Red Temática de Toxicología de Plaguicidas (CONACyT280045).

\section{REFERENCIAS}

Abdel-Razek M.A., Folch-Mallol J.L., PerezgasgaCiscomani L., Sánchez-Salinas E., Castrejón-Godínez M.L. y Ortiz-Hernández M.L. (2013). Optimization of methyl parathion biodegradation and detoxification by cells in suspension or immobilized on tezontle expressing the opd gene. J. Environ. Sci. Heal. B. 48 (6), 449-461. DOI: 10.1080/03601234.2013.761863

Aceves-Diez A.E., Estrada-Castañeda K.J. y CastañedaSandoval L.M. (2015). Use of Bacillus thuringiensis supernatant from a fermentation process to improve bioremediation of chlorpyrifos in contaminated soils. J. Environ. Manage.157, 213-219.

DOI: 10.1016/j.jenvman.2015.04.026

Acosta-Maldonado B., Sánchez-Ramírez B., Reza-López S. y Levario-Carrillo M. (2009). Effects of exposure to pesticides during pregnancy on placental maturity and weight of newborns: a cross-sectional pilot study in women from the Chihuahua State, Mexico. Hum. Exp. Toxicol. 28 (8), 451-459.

DOI: $10.1177 / 0960327109107045$

Aguilar-Garduño C., Lacasaña M., Blanco-Muñoz J., Rodríguez-Barranco M., Hernández A.F., Bassol S., González-Alzaga B. y Cebrián M.E. (2013). Changes in male hormone profile after occupational organophosphate exposure. A longitudinal study. Toxicology 307, 55- 65. DOI: 10.1016/j.tox.2012.11.001

Aguilera-González C.A., Cruz J. y Alfaro R.M. (2015). Physiological response of alligator gar juveniles (Atractosteus spatula). Fish Physiol. Biochem. 41 (4), 1015-1027.

DOI: $10.1007 / \mathrm{s} 10695-015-0066-5$

Aguirre A.A., Balazs G.H., Zimmerman B. y Galey F.D. (1994). Organic contaminants and trace metals in the tissues of green turtles (Chelonia mydas) afflicted with fibropapillomas in the Hawaiian Islands. Mar. Pollut. Bull. 28 (2), 109-114. DOI: 10.1289/ehp.8143

Albores A., Ortega-Mantilla G., Sierra-Santoyo A., Cebrián M.E., Muñoz-Sánchez J.L., Calderón-Salinas J.V. y Manno M. (2001). Cytochrome P450 2B (CYP2B)mediated activation of methyl-parathion in rat brain 
extracts. Toxicol. Lett. 124 (1), 1-10.

DOI: $10.1016 / \mathrm{S} 0378-4274(01) 00382-4$

Aldana L., Tsutsumi V., Craigmill A., Silveira M.I. y González de Mejía E. (2001). $\alpha$-tocopherol modulates liver toxicity of the pyrethroid cypermethrin. Toxicol. Lett. 125 (1), 107-116. DOI: $10.1016 / \mathrm{S} 0378-4274(01) 00427-1$

Aldana-Madrid M.L., Mendívil-Gil C.I., Mada-González C.D., Silveira-Gramont M.I. y Navarro-Henze J.L. (2003) Alteraciones en el análisis del líquido seminal de aplicadores de insecticidas en el medio urbano. Acta Méd. Son. 4 (4), 5-7.

Aldana-Madrid M.L., Valdez-Hurtado S., Vargas-Valdez N.D., Salazar-López N.J., Silveira-Gramont M.I., Loarca-Piña F.G., Rodríguez-Olibarria G., WongCorral F.J., Borboa-Flores E. y Burgos-Hernández A. (2008a). Insecticide residues in stored grains in Sonora, Mexico: quantification and toxicity testing. Bull. Environ. Contam. Tox. 80 (2), 93-96.

DOI: $10.1007 / \mathrm{s} 00128-007-9302-8$

Aldana-Madrid M.L., García-Moraga M.D.C., RodríguezOlibarria G., Silveira-Gramont M.I. y ValenzuelaQuintanar A.I. (2008b). Determinación de insecticidas organofosforados en nopal fresco y deshidratado. Rev. Fitotec. Mex. 31(2), 133-139.

Aldana-Madrid M.L., Valenzuela-Quintanar A.I., SilveiraGramont M.I., Rodríguez-Olibarría G., Grajeda-Cota P., Zuno-Floriano F.G. y Miller M.G. (2011). Residual pyrethroids in fresh horticultural products in Sonora, Mexico. Bull. Environ. Contam. Tox. 87 (4), 436-439. DOI: 10.1007/s00128-011-0391-z

Alegría H., Bidleman T.F. y Figueroa M.S. (2006). Organochlorine pesticides in the ambient air of Chiapas, Mexico. Environ. Pollut. 140 (3), 483-491.

DOI: 10.1016/j.envpol.2005.08.007

Alegría-Torres J.A., Díaz-Barriga F., Gandolfi A.J. y Pérez-Maldonado I.N. (2009). Mechanisms of p,p'DDE-induced apoptosis in human peripheral blood mononuclear cells. Toxicol. In Vitro. 23 (6), 10001006. DOI: 10.1016/j.tiv.2009.06.021

Alvarado-Flores J., Rico-Martínez R., Adabache-Ortíz A. y Silva-Briano M. (2015). Morphological alterations in the freshwater rotifer Brachionus calyciflorus Pallas 1766 (Rotifera: Monogononta) caused by vinclozolin chronic exposure. Ecotoxicology 24 (4), 915-925. DOI: $10.1007 / \mathrm{s} 10646-015-1434-8$

Amaya-Chávez A., Martínez-Tabche L., López-López E. y Galar-Martínez M. (2006). Methyl parathion toxicity to and removal efficiency by Typha latifolia in water and artificial sediments. Chemosphere 63 (7), 1124-1129. DOI: 10.1016/j.chemosphere.2005.09.049

Amaya-Chávez A., López-López E., Galar-Martínez M., Gómez-Oliván, L.M. y García-Fabila M.M. (2009).
Removal of methyl parathion in water, by Dugesia dorotocephala. Bull. Environ. Contam. Tox. 83(3), 334-336.

DOI: $10.1007 / \mathrm{s} 00128-009-9741-5$

Anguiano G., Llera-Herrera R., Rojas E. y VazquezBoucard C. (2007). Subchronic organismal toxicity, cytotoxicity, genotoxicity, and feeding response of pacific oyster (Crassostrea gigas) to lindane $(\gamma-\mathrm{HCH})$ exposure under experimental conditions. Environ. Toxicol. Chem. 26 (10), 2192-2197.

DOI: $10.1897 / 06-377 R 3.1$

Anguiano G.A., Amador A., Moreno-Legorreta M., Arcos-Ortega F. y Vazquez-Boucard C. (2010). Effects of exposure to oxamyl, carbofuran, dichlorvos, and lindane on acetylcholinesterase activity in the gills of the Pacific oyster Crassostrea gigas. Environ. Toxicol. 25 (4), 327-332. DOI: 10.1002/tox.20491

Arellano-Aguilar O. y Rendón von Osten J. (2017). La huella de los plaguicidas en México. [en línea] http://m. greenpeace.org/mexico/Global/mexico/Graficos/2016/ comida-sana/Plaguicidas_en_agua_ok_EM.pdf 06/05/2017

Arellano García M.E., Camarena Ojinaga L., Von-Glascoe C.A., Ruiz Ruiz B., Zúñiga Violante E. y Montaño Soto T. (2013). Daño genotóxico en mujeres y hombres expuestos en cuatro localidades de Baja California. En: Género, ambiente y contaminación por sustancias químicas. Secretaría de Medio Ambiente y Recursos Naturales (SEMARNAT). Instituto Nacional de Ecología, México, pp. 95-113.

Arias-Almeida J.C. y Rico-Martínez R. (2011). Toxicity of cadmium, lead, mercury and methyl parathion on Euchlanis dilatata Ehrenberg 1832 (Rotifera: Monogononta). Bull. Environ. Contam. Tox. 87 (2), 138-142. DOI: 10.1007/s00128-011-0308-x

Arrona-Rivera A.E., Enríquez P.L., García-Feria L.M., Alvarado-Orellana S. y Rendón von Osten J. (2016). Organochlorine pesticides in the ferruginous pygmy owl (Glaucidium brasilianum) in Chiapas, México. Bull. Environ. Contam. Tox. 97 (3), 337-345.

DOI: $10.1007 / \mathrm{s} 00128-016-1861-0$

Arteaga-Gómez E., Rodríguez-Levis A., Cortés-Eslava J., Arenas-Huertero F., Valencia-Quintana R. y GómezArroyo S. (2016). Cytogenotoxicity of selected organophosphate insecticides on HaCaT keratinocytes and NL-20 human bronchial cells. Chemosphere 145, 174-184.

DOI: 10.1016/j.chemosphere.2015.11.043

Bejarano-González F. (2017). Los plaguicidas altamente peligrosos nuevo tema normativo internacional y su perfil nacional en México. En: Los plaguicidas altamente peligrosos en México. (Bejarano-González F. Ed.). RAPAM, CIAD, Red Temática de Toxicología 
de Plaguicidas, UAEMEX, INIFAP, UCCS, IPEN, PNUD. México, pp: 10-96.

Benítez-Trinidad A.B., Herrera-Moreno J.F., Vázquez-Estrada G., Verdín- Betancourt F.A., Sordo M., Ostrosky P., Bernal-Hernández Y.Y., Medina-Díaz I.M., BarrónVivanco B.S., Robledo-Marenco M.L., Salazar A.M. y Rojas-García A.E. (2015). Cytostatic and genotoxic effect of temephos in human lymphocytes and HepG2 cells. Toxicol. In vitro. 29 (4), 779-86.

DOI: $10.1016 /$ j.tiv.2015.02.008

Bernal-Hernández Y.Y., Medina-Díaz I.M., RobledoMarenco M.L., Velázquez-Fernández J.B., Girón-Pérez M.I., Ortega-Cervantes L., Maldonado-Vázquez W.A. y Rojas-García A.E. (2010). Acetylcholinesterase and metallothionein in oysters (Crassostrea corteziensis) from a subtropical Mexican Pacific estuary. Ecotoxicology 19 (4), 819-825.

DOI: $10.1007 / \mathrm{s} 10646-009-0459-2$

Bernal-Hernández Y.Y., Medina-Díaz I.M., Barrón-Vivanco B.S., Robledo-Marenco M., Girón-Pérez M.I., Pérez-Herrera N.E., Quintanilla-Vega B., Cerda-Flores R. y Rojas-García A.E. (2014). Paraoxonase 1 and its relationship with pesticide biomarkers in indigenous Mexican farmworkers. J. Occup. Environ. Med. 56 (3), 281-90. DOI: 10.1097/01.jom.0000438381.25597.88

Bernardino-Hernández H.U., Mariaca-Méndez R., NazarBeutelspacher A., Álvarez-Solís J.D., Torres-Dosal A. y Herrera-Portugal C. (2017). Los plaguicidas altamente peligrosos en los Altos de Chiapas. En: Los plaguicidas altamente peligrosos en México. (Bejarano-González F. Ed.). RAPAM, CIAD, Red Temática de Toxicología de Plaguicidas, UAEMEX, INIFAP, UCCS, IPEN, PNUD. México, pp: 219-230.

Betancourt-Lozano M., Baird D.J., Sangha R.S. y González-Farias F. (2006). Induction of morphological deformities and moulting alterations in Litopenaeus vannamei (Boone) juveniles exposed to the triazolederivative fungicide tilt. Arch. Environ. Contam. Toxicol. 51 (1), 69-78. DOI: 10.1007/s00244-005-0149-x

Blanco-Muñoz J., Morales M.M., Lacasaña M., AguilarGarduño C., Bassol S. y Cebrian M.E. (2010). Exposure to organophosphate pesticides and male hormone profile in floriculturist of the state of Morelos, Mexico. Hum. Reprod. 25 (7), 1787-1795.

DOI: $10.1093 /$ humrep/deq082

Blanco-Muñoz J., Aguilar-Garduño C., Gamboa-Avila R., Rodríguez-Barranco M., Pérez-Méndez O., HuescaGómez C., González-Alzaga B. y Lacasaña M. (2013). Association between PON1 genetic polymorphisms and miscarriage in Mexican women exposed to pesticides. Sci. Total Environ. 449, 302-308.

DOI: 10.1016/j.scitotenv.2013.01.034

Blanco-Muñoz J., Lacasaña M., López-Flores I., Rodrí-
guez-Barranco M., González-Alzaga B., Bassol S., Cebrian M.E., López-Carrillo L. y Aguilar-Garduño C. (2016). Association between organophosphate pesticides exposure and thyroid hormones in floriculture workers. Toxicol. Appl Pharm. 243 (1), 19-26.

DOI: 10.1016/j.taap.2009.11.008

Bonilla E., Hernández F., Cortés L., Mendoza M., Mejía J., Carrillo E., Casas E. y Betancourt M. (2008). Effects of the insecticides malathion and diazinon on the early oogenesis in mice in vitro. Environ. Toxicol. 23 (2), 240-245.

DOI: $10.1002 /$ tox. 20332

Borrell A., Cantos G., Pastor T. y Aguilar A. (2001). Organochlorine compounds in common dolphins (Delphinus delphis) from the Atlantic and Mediterranean waters of Spain. Environ. Pollut. 114 (2), 265-274. DOI: 10.1016/S0269-7491(00)00213-X

Borrell A. y Aguilar A. (2005). Differences in DDT and PCB residues between common and striped dolphins from the southwestern Mediterranean. Arch. Environ. Contam. Toxicol. 48 (4), 501-508. DOI: $10.1007 / \mathrm{s} 00244-004-0039-7$

Botello A.V., Ruede-Quintana L., Diaz-González G. y Toledo A. (2000). Persistent organochlorine pesticides (POPs) in coastal lagoons of the subtropical Mexican Pacific. Bull. Environ. Contam. Tox. 64 (3), 390-397. DOI: $10.1007 / \mathrm{s} 001280000013$

Burgos-Hernández A., Leyva-Zapién M.G., AldanaMadrid M.A., García-Sifuentes C.O. Mendívil-Gil C.I., Rosas-Burgos E.K. y Ramírez-Olivas R. (2006). Presence of insecticides in shrimp farms adjacent to the Sea of Cortés: detection, quantification, and toxicity testing. Eur. Food Res. Technol. 222 (3-4), 380-384. DOI: $10.1007 / \mathrm{s} 00217-005-0012-3$

Bustamante-Montes L.P., Waliszewski S., HernándezValero M., Sanín-Aguirre L., Infanzón-Ruiz R.M. y García-Jañas A. (2010). Exposición prenatal a los plaguicidas organoclorados y criptorquidia. Cienc. Saúde Coletiva. 15,1169-1174.

DOI: $10.1590 / \mathrm{S} 1413-81232010000700025$

Camarena-Ojinaga L., Von-Glascoe C., Martínez-Valdés C. y Arellano-García E. (2013). Riesgos del trabajo y salud: percepción de mujeres indígenas jornaleras en el noroeste de México. Salud Colect. 9 (2), 247-256.

Carbajal-López Y., Gómez-Arroyo S., Villalobos-Pietrini R., Calderón-Segura M.E. y Martínez-Arroyo A. (2016). Biomonitoring of agricultural workers exposed to pesticide mixtures in Guerrero state, Mexico, with comet assay and micronucleus test. Environ. Sci. Pollut. R. 23 (3), 2513-2520.

DOI: $10.1007 / \mathrm{s} 11356-015-5474-7$

Carvalho F.P., González-Farías F., Villeneuve J.P., Cattini C., Hernández-Garza M., Mee L.D. y Fowler 
S.W. (2002) Distribution, fate and effects of pesticide residues in tropical coastal lagoons of northwestern México. Environ. Technol. 23 (11), 1257-1270.

DOI: 10.1080/09593332308618321

Castillo C.G., Montante M., Dufour L., Martínez M.L. y Jiménez-Capdeville M.E. (2002). Behavioral effects of exposure to endosulfan and methyl parathion in adult rats. Neurotoxicol. Teratol. 24 (6), 797-804.

DOI: $10.1016 / \mathrm{S} 0892-0362(02) 00268-4$

Castillo-Cadena J., Tenorio-Vieyra L.E., Quintana-Carabia A.I., García-Fabila M.M., Juan E.R., MadrigalBujaidar E. (2006). Determination of DNA damage in floriculturists exposed to mixtures of pesticides. J. Biomed. Biotechnol. 2006, 1-12.

DOI: $10.1155 / \mathrm{JBB} / 2006 / 97896$

Castillo-Cadena J. y Montenegro-Morales L.P. (2017). El uso de plaguicidas altamente peligrosos en la floricultura en el Estado de México y el efecto sinérgico de las mezclas. En: Los plaguicidas altamente peligrosos en México. (Bejarano-González F. Ed). RAPAM, CIAD, Red Temática de Toxicología de Plaguicidas, UAEMEX, INIFAP, UCCS, IPEN, PNUD. México, pp: 203-218.

Castillo-Sosa Y., Sierra-Fonseca A., Martínez-Martínez A. y Plenge-Tellechea F. (2009). Efecto del diazinón sobre el cultivo de linfocitos de sangre periférica de humano. Tecnociencia Chihuahua 3 (2), 97-106.

Chaín-Castro T.J., Barrón-Aragón R. y Haro-García L. (1998). Pesticide poisoning in Mexican seasonal farm workers. Int. J. Occup. Env. Heal. 4 (3), 202-203. DOI: 10.1179/oeh.1998.4.3.202

Chávez-Almazán L.A., Díaz-Ortiz J., Alarcón-Romero M., Dávila-Vazquez G., Saldarriaga-Noreña H. y Waliszewski S.M. (2014). Organochlorine pesticide levels in breast milk in Guerrero, Mexico. Bull. Environ. Contam. Tox. 93 (3), 294-298.

DOI: $10.1007 / \mathrm{s} 00128-014-1308-4$

CICOPLAFEST (2016). Catálogo oficial de plaguicidas. Comisión Intersecretarial para el Control del Proceso y Uso de Plaguicidas, Fertilizantes y Sustancias Tóxicas. Ciudad de México, 664 pp.

Cobos V.M., Mora M.A. y Escalona G. (2006). Inhibición de colinesterasa plasmática en el zorzal pardo (Turdus grayi), expuesto a diazinón en cultivos de papaya maradol en Yucatán, México. Rev. Toxicol. 23 (1), 17-21.

Cobos-Gasca V.M., Barrientos-Medina R. y Chi-Novelo C. (2011). Los plaguicidas y su impacto sobre la fauna silvestre de la Península de Yucatán. Bioagrociencias 4 (2), 4-9.

Comoglio L., Amin O., Roque A., Betancourt-Lozano M., Anguas D. y Haro B.M. (2005). Evaluation of sublethal biomarkers in Litopenaeus vannamei on foodborne exposure to methyl parathion. Ecotox. Environ. Safe.
62(1), 66-74. DOI: 10.1016/j.ecoenv.2004.10.006

Cortés-Eslava J., Gómez-Arroyo S., Arenas-Huertero F., Flores-Maya S., Díaz-Hernández M.E., Calderón-Segura M.E., Valencia-Quintana R., Espinosa-Aguirre J.J. y Villalobos-Pietrini R. (2013). The role of plant metabolism in the mutagenic and cytotoxic effects of four organophosphorus insecticides in Salmonella typhimurium and in human cell lines. Chemosphere 92 (9), 1117-1125.

DOI: 10.1016/j.chemosphere.2013.01.058

Del Toro L., Heckel G., Camacho-Ibar V.F. y Schramm Y. (2006). California sea lions (Zalophus californianus californianus) have lower chlorinated hydrocarbon contents in northern Baja California, México, than in California, USA. Environ. Pollut. 142 (1), 83-92. DOI: 10.1016/j.envpol.2005.09.019

Díaz-Resendiz K.J.G., Toledo-Ibarra G.A. y Girón-Pérez M.I. (2015). Modulation of immune response by organophosphorus pesticides: fishes as a potential model in immunotoxicology. J. Immunol. Res. 2015, 1-10. DOI: $10.1155 / 2015 / 213836$

Díaz-Romo P. y Salinas-Álvarez S. (2002). Huicholes y plaguicidas. Informe Proyecto Huicholes y Plaguicidas 1983-2002. [en línea] http://hypinfo.org/documentos/ hyp_informe_historial.pdf 02/02/2017

Dirección General de Epidemiología (DGE). (2017). Anuario de Morbilidad 1984- 2016 [en línea] http://www. epidemiologia.salud.gob.mx/anuario/html/anuarios. html 02/02/2017

Domínguez-López P., Díaz-Cueto L., Olivares A., UlloaAguirre A. y Arechavaleta-Velasco F. (2012). Differential effect of DDT, DDE, and DDD on COX-2 expression in the human trophoblast derived HTR-8/ SVneo cells. J. Biochem. Mol. Toxic. 26 (11), 454-460. DOI: $10.1002 / j b t .21444$

Dzul-Caamal R., Domínguez-López M. L., García-Latorre E. y Vega-López A. (2012). Implications of cytochrome 450 isoenzymes, aryl-esterase and oxonase activity in the inhibition of the acetylcholinesterase of Chirostoma jordani treated with phosphorothionate pesticides. Ecotox. Environ. Safe. 84, 199-206.

DOI: 10.1016/j.ecoenv.2012.07.008

Eaton D.L. y Gilbert S.G. (2013). Principles of toxicology. En: Casarett and Doull's toxicology: the basic science of poisons. (C.D. Klaassen, 8th Ed.). McGraw-Hill Education, China, pp. 13-48.

DOI: $10.1036 / 0071470514$

Eto M. (1974). Organophosphorus pesticides: organic and biological chemistry, CRS Press, Cleveland. 387 pp. DOI.org/10.1093/besa/21.4.266

Esquivel-Sentíes M.S., Barrera I., Ortega A. y Vega L. (2010). Organophosphorous pesticide metabolite (DEDTP) induces changes in the activation status of 
human lymphocytes by modulating the interleukin 2 receptor signal transduction pathway. Toxicol. Appl. Pharm. 248 (2), 122-133.

DOI: $10.1016 /$ j.taap.2010.07.017

FAO (Food and Agriculture Organization of the United Nations). (2015). FAOSTAT [en línea]. http://www. fao.org/faostat/en/\#home 03/02/17

FAO (Food and Agriculture Organization of the United Nations). (2017). FAOSTAT [en línea]. http://www. fao.org/faostat/en/\#data/EP 03/02/17

Fortenberry G.Z., Meeker J.D., Sánchez B.N., Barr D.B., Panuwet P., Bellinger D., Schnaas L., Solano-González M., Ettinger A.S., Hernández-Avila M., Hu H., TellezRojo M.M. (2014). Urinary 3,5,6-trichloro-2-pyridinol (TCPY) in pregnant women from México City: distribution, temporal variability, and relationship with child attention and hyperactivity. Int. J. Hyg. Envir. Heal. 217 (2), 405-412. DOI: 10.1016/j.ijheh.2013.07.018

Galindo-Reyes J.G., Medina J.A., Villagrana L.C. e Ibarra C.L. (1997). Enviromental and pollution condition of the Huizache-Caimanero lagoon in the north- west of México. Mar. Pollut. Bull. 34 (12), 1072-1077.

DOI: $10.1016 / \mathrm{S} 0025-326 \mathrm{X}(97) 00081-7$

Galindo-Reyes G., Villagrana-L.C. y Lazcano-Alvarez G. (1999). Environmental conditions and pesticide pollution of two coastal ecosystems in the Gulf of California, Mexico. Ecotox. Environ. Safe. 44 (3), 280-286.

DOI: 10.1006/eesa.1999.1836

Galindo-Reyes J., Leyva N.R., Millan O.A. y Lazcano G.A. (2002). Effects of pesticides on DNA and protein of shrimp larvae Litopenaeus stylirostris of the California Gulf. Ecotox. Environ. Safe. 53 (2), 191-195.

DOI: $10.1006 /$ eesa.2002.2156

Gallo-Reynoso J.P., Malek T.B., García-Hernández J., Vázquez-Moreno L. y Segura-García I. (2014). Concentrations of DDE in blubber biopsies of free-ranging long-beaked common dolphins (Delphinus capensis) in the Gulf of California. Bull. Environ. Contam. Tox. 94(1), 6-11.

DOI: $10.1007 / \mathrm{s} 00128-014-1414-3$

Gama-Flores J.L., Sarma S.S.S. y Fernández-Araiza M.A. (1999). Combined effects of Chlorella density and methyl parathion concentration on the population growth of Brachionus calyciflorus (Rotifera). Bull. Environ. Contam. Tox. 62 (6), 769-775.

DOI: $10.1007 / \mathrm{s} 001289900938$

Gamlin J., Diaz-Romo P. y Hesketh T. (2006). Exposure of young children working on Mexican tobacco plantations to organophosphorous and carbamic pesticides, indicated by cholinesterase depression. Child Care Hlth. Dev. 33 (3), 246-8.

DOI: $10.1111 / \mathrm{j} .1365-2214.2006 .00702 . x$
García-Besné G., Valdespino C. y Rendón von Osten J. (2015). Comparison of organochlorine pesticides and PCB residues among hawksbill (Eretmochelys imbricata) and green (Chelonia mydas) turtles in the Yucatan Peninsula and their maternal transfer. Mar. Pollut. Bull. 91 (1), 139-148.

DOI: 10.1016/j.marpolbul.2014.12.015

García de la Parra L.M., Bautista-Covarrubias J.C., Riverade la Rosa N., Betancourt-Lozano M. y Guilhermino L. (2006). Effects of methamidophos on acetylcholinesterase activity, behavior, and feeding rate of the white shrimp (Litopenaeus vannamei). Ecotox. Environ. Safe. 65 (3), 372-380.

DOI: 10.1016/j.ecoenv.2005.09.001

García de la Parra L.M., Cervantes-Mojica L.J., GonzálezValdivia C., Martínez-Cordero F.J., Aguilar-Zarate G., Bastidas-Bastidas P. y Betancourt-Lozano M. (2012). Distribution of pesticides and PCBs in sediments of agricultural drains in the Culiacan Valley, Sinaloa, Mexico. Arch. Environ. Con. Tox. 63 (3), 323-336. DOI: $10.1007 / \mathrm{s} 00244-012-9780-5$

García de la Parra L.M., González-Valdivia C., CervantesMojica L.J., Aguilar-Zárate G., Bastidas-Bastidas P. y Betancourt-Lozano M. (2014). Plaguicidas y PCBs en sedimentos de granjas camaronícolas en un sistema costero de Sinaloa, México. En: Pacífico Mexicano. Contaminación e impacto ambiental: diagnóstico y tendencias (A.V. Botello, F. Páez-Osuna, L. MéndezRodríguez, M. Betancourt-Lozano, S. Álvarez-Borrego y R. Lara-Lara Eds.). UAC, UNAM-ICMyL, CIADMAZATLÁN, CIBNOR, CICESE. México, pp: 57-72.

García-Hernández J., Sapozhnikova Y.V., Schlenk D., Mason A.Z., Hinojosa-Huerta O., Rivera-Díaz J.J., Ramos-Delgado N.A. y Sánchez-Bon G. (2006). Concentration of contaminants in breeding bird eggs from the Colorado River Delta, México. Environ. Toxicol. Chem. 25 (6), 1640-1647. DOI: 10.1897/05-185R.1

García-Hernández J., Glenn E.P. y Flessa K. (2013). Identification of chemicals of potential concern (COPECs) in anthropogenic wetlands of the Colorado River delta. Ecol. Eng. 59, 52-60.

DOI: 10.1016/j.ecoleng.2013.04.045

García-Hernández J., Espinosa-Romero M.J., CisnerosMata M.A., Leyva-García G., Aguilera-Márquez D. y Torre-Cosío J. (2015). Concentración de mercurio y plaguicidas organoclorados (poc) en tejido comestible de jaiba café Callinectes bellicosus de las costas de Sonora y Sinaloa, México. Ciencia Pesquera 23, 65-79.

García-Hernández J., Leyva-García G. y AguileraMárquez D. (2017). Los plaguicidas altamente peligrosos en el Valle del Yaqui, Sonora. En: Los plaguicidas altamente peligrosos en México. (Bejarano-González F. Ed.). RAPAM, CIAD, Red Temática de Toxicología 
de Plaguicidas, UAEMEX, INIFAP, UCCS, IPEN, PNUD. México, pp: 173-183.

Gardner S.C., Dawn Pier M., Wesselman R. y Juárez J.A. (2003). Organochlorine contaminants in sea turtles from the Eastern Pacific. Mar. Pollut. Bull. 46 (9), 1082-1089. DOI: 10.1016/S0025-326X(03)00254-6

Garza-Robledo A.A., Martínez-Perales J.F., RodríguezCastro V.A. y Quiroz-Martínez H. (2011). Effectiveness of spinosad and temephos for the control of mosquito larvae at a tire dump in Allende, Nuevo Leon, Mexico. J. Am. Mosquito Contr. 27 (4), 404-407. DOI: $10.2987 / 11-6133.1$

Gold-Bouchot G., Ceja-Moreno V., Chan-Cocom E. y Zapata-Pérez O. (2013). Petroleum hydrocarbons, fluorescent aromatic compounds in fish bile and organochlorine pesticides from areas surrounding the spill of the Kab121 well, in the southern Gulf of México: a case study. J. Environ. Biol. 35 (1), 147-56. PMID: 24579530

Gómez-Arroyo S., Díaz-Sánchez Y., Meneses-Pérez M.A., Villalobos-Pietrini R. y De León-Rodríguez J. (2000). Cytogenetic biomonitoring in a Mexican floriculture worker group exposed to pesticides. Mutat. Res. 466 (1), 117-124. DOI: 10.1016/S1383-5718(99)00231-4

Gómez-González I. (2017). El uso de los plaguicidas altamente peligrosos en la Península de Yucatán. En: Los plaguicidas altamente peligrosos en México. (Bejarano-Gonzalez F. Ed.). RAPAM, CIAD, Red Temática de Toxicología de Plaguicidas, UAEMEX, INIFAP, UCCS, IPEN, PNUD. México, pp: 231-253.

González-Arias C.A., Robledo-Marenco M.A., MedinaDíaz I.M., Velázquez-Fernández J.B., Girón-Pérez M.I., Quintanilla-Vega B., Ostrosky-Wegman P., PérezHerrera N.E. y Rojas-García A.E. (2010). Patrón de uso y venta de plaguicidas en Nayarit, México. Rev. Int. Contam. Ambie. 26 (3), 221-228.

González-Escalante L., Mercado-Hernández R., GonzálezRojas J.I. y Bermúdez de León M. (2013). Plasma cholinesterase activity in the house finch, Carpodacus mexicanus, and the house sparrow, Passer domesticus, collected from pesticide-exposed agricultural land. Bull. Environ. Contam. Tox. 90 (1), 9-11.

DOI: $10.1007 / \mathrm{s} 00128-012-0864-8$

González-Farias F., Cisneros Estrada X., Fuentes Ruíz C., Díaz González G. y Botello A.V. (2002). Pesticides distribution in sediments of a tropical coastal lagoon adjacent to an irrigation district in northwest Mexico. Environ. Technol. 23 (11), 1247-56. DOI: $10.1080 / 09593332308618323$

González-Jaúregui M., Valdespino C., Salame-Méndez A., Aguirre-León G. y Rendón-von Osten J. (2012). Persistent Organic contaminants and steroid hormones levels in Morelet's crocodiles from the southern Gulf of México. Arch. Environ. Con. Tox. 62 (3), 445-54. DOI: $10.1007 / \mathrm{s} 00244-011-9716-5$

González-Mille D.J., Ilizaliturri-Hernández C.A., Espinosa-Reyes G., Costilla-Salazar R., Díaz-Barriga F., Ize-Lema I. y Mejía-Saavedra J. (2010). Exposure to persistent organic pollutants (POPs) and DNA damage as an indicator of environmental stress in fish of different feeding habits of Coatzacoalcos, Veracruz, México. Ecotoxicology19 (7), 1238-1248. DOI: $10.1007 / \mathrm{s} 10646-010-0508-\mathrm{x}$

Goutner V.T., Frigis K., Konstantinou I.S., Sakellarides T. y Albanis T. (2012) Organochlorine pesticide residue concentrations and accumulation patterns in waterbirds and in their prey at Lake Kerkini, a Ramsar wetland, Greece. J. Biol. Res.-Thessaloniki. 17, 154-168.

Granados-Galván I.A., Rodríguez-Meza D.G., LunaGonzález A. y González-Ocampo H.A. (2015). Human health risk assessment of pesticide residues in snappers (Lutjanus) fish from the Navachiste Lagoon complex, Mexico. Mar. Pollut. Bull. 97 (1), 178-187. DOI: 10.1016/j.marpolbul.2015.06.018

Guillén-Garcés R.A., Hansen A.M. y Van Afferden M. (2007). Mineralization of atrazine in agricultural soil: inhibition by nitrogen. Environ. Toxicol. Chem. 26 (5), 844-850. DOI: 10.1897/06-328R.1

Guillette E.A., Meza M.M., Aquilar M.G., Soto A.D., Garcia I.E. (1998). An anthropological approach to the evaluation of children exposed to pesticides in Mexico. Environ. Health Persp. 106 (6), 347-353. PMC1533004

Guillette E.A., Conard C., Lares F., Aguilar M.G., McLachlan J. y Guillette L.J.Jr. (2006). Altered breast development in young girls from an agricultural environment. Environ. Health Persp. 114 (3), 471-475. DOI: $10.1289 /$ ehp. 8280

Gutiérrez R., Ortiz R., Vega S., Schettino B., Ramírez M.L. y Pérez J.J. (2013). Residues levels of organochlorine pesticide in cow's milk from industrial farms in Hidalgo, Mexico. J. Environ. Sci. Heal. B. 48 (11), 935-940.

DOI: $10.1080 / 03601234.2013 .816592$

Gutiérrez R.F., Santiesteban A., Cruz-López L. y BelloMendoza R. (2007). Removal of chlorothalonil, methyl parathion and methamidophos from water by the Fenton reaction. Environ. Technol. 28 (3), 267-272. DOI: $10.1080 / 09593332808618787$

Hayteas D.L. y Duffield D.A. (1997). The determination by HPLC of PCB and p, $\mathrm{p}^{\prime}$-DDE residues in marine mammals stranded on the Oregon Coast, 1991-1995. Mar. Poll. Bull. 34 (10), 844-848. DOI: $10.1016 / \mathrm{S} 0025-326 \mathrm{X}(97) 00045-3$

Hernández-Antonio A. y Hansen A.M. (2011). Uso de plaguicidas en dos zonas agrícolas de México y evaluación de la contaminación de agua y sedimentos. Rev. Int. Contam. Ambie. 27 (2), 115-127. 
Hernández-Plata I., Giordano M., Díaz-Muñoz M. y Rodríguez V.M. (2015). The herbicide glyphosate causes behavioral changes and alterations in dopaminergic markers in male Sprague-Dawley rat. Neurotoxicology 46, 79-91. DOI: 10.1016/j.neuro.2014.12.001

Hernández-Romero A.H., Tovilla-Hernández C., Malo E.A. y Bello-Mendoza R. (2004). Water quality and presence of pesticides in a tropical coastal wetland in southern Mexico. Mar. Pollut. Bull. 48 (11), 11301141. DOI: 10.1016/j.marpolbul.2004.01.003

Herrera-Portugal C., Ochoa H., Franco-Sánchez G., Yañez L. y Díaz-Barriga F. (2005). Environmental pathways of exposure to DDT for children living in a malarious area of Chiapas, México. Environ. Res. 99 (2), 158163. DOI: $10.1016 /$ j.envres.2005.03.010

Hobbs K.E., Muir D.C.G., Born E.W., Dietz R., Haug T., Metcalfe T., Metcalfe C. y Øien N. (2003). Levels and patterns of persistent organochlorines in minke whale (Balaenoptera acutorostrata) stocks from the North Atlantic and European Arctic. Environ. Pollut. 121 (2), 239-252. DOI: DOI: 10.1016/S0269-7491(02)00218-X Infante-Rodríguez D.A., Novelo-Gutiérrez R., Mercado G. y Williams T. (2011). Spinosad toxicity to Simulium spp. larvae and associated aquatic biota in a coffeegrowing region of Veracruz State, Mexico. Mutat. Res. 48 (3), 570-576.

DOI: 10.1603/ME10099

Islas-González K., González-Horta C., Sánchez-Ramírez B., Reyes-Aragón E. y Levario-Carrillo M. (2005). In vitro assessment of the genotoxicity of ethyl paraoxon in newborns and adults. Hum. Exp. Toxicol. 24 (6), 319-324. DOI: 10.1191/0960327105ht534oa

Islas-García A., Vega-Loyo L., Aguilar-López R., Xoconostle-Cázares B. y Rodríguez-Vázquez R. (2015). Evaluation of hydrocarbons and organochlorine pesticides and their tolerant microorganisms from an agricultural soil to define its bioremediation feasibility. J. Environ. Sci. Heal. B. 50 (2), 99-108.

DOI: 10.1080/03601234.2015.975605

Jasso-Pineda Y., Díaz-Barriga F., Yáñez-Estrada L., Pérez-Vázquez F.J., Pérez-Maldonado I.N. (2015). DNA damage in Mexican children living in high-risk contaminated scenarios. Sci. Total Environ. 518, 38-48. DOI: 10.1016/j.scitotenv.2015.02.073

Jiménez-Castro C., Mellink E. y Villaescusa-Celaya J. (1995). DDT and its metabolites in western gull eggs from southern California and northwestern Baja California. Bull. Environ. Contam. Tox. 55 (3), 374-381. DOI: $10.1007 / B F 00206675$

Kegley S.E., Hill B.R., Orme S. y Choi A.H. (2016). PAN Pesticide Database, Pesticide Action Network, North America San Francisco, CA [en línea]. http://www. pesticideinfo.org/ 09/12/2016.
Keller J., Kucklick J., Harms C. y McClellan-Green P. (2004a). Organochlorine contaminants in sea turtles: correlations between whole blood and fat. Environ. Toxicol. Chem. 23 (3), 726-738. DOI: 10.1897/03-254

Keller J., Kucklick J. y McClellan-Green P. 2004b. Organochlorine contaminants in loggerhead sea turtle blood: extraction techniques and distribution among plasma and red blood cells. Arch. Environ. Contam. Toxicol. 46 (2), 254-264. DOI: 10.1007/s00244-003-2262-z

Koepke R., Warner M., Petreas M., Cabria A., Danis R., Hernandez-Avila M. y Eskenazi B. (2004). Serum DDT and DDE levels in pregnant women of Chiapas, Mexico. Arch. Environ. Health. 59 (11), 559-565.

DOI: $10.1007 /$ BF00206675

Lacasaña M., Vázquez-Grameix H., Borja-Aburto V.H., Blanco-Muñoz J., Romieu I., Aguilar-Garduño C. y García A.M. (2006). Maternal and paternal occupational exposure to agricultural work and the risk of anencephaly. Occup. Environ. Med. 63 (10), 649-656. DOI: 10.1136/oem.2005.023333

Leal-Soto S. D., Valenzuela-Quintanar A. I., GutiérrezCoronado M. L., Bermúdez-Almada M.C., GarcíaHernández J., Aldana Madrid M.L., Grajeda-Cota P., Silveira-Gramont M.I., Meza-Montenegro M.M., Palma-Durán S.A., Leyva-García G.N., Camarena-Gómez B.O. y Valenzuela-Navarro C.P. (2013). Residuos de plaguicidas organoclorados en suelos agrícolas. Terra Latinoamericana 32, 1-11.

Levario-Carrillo M., Amato D., Ostrosky-Wegman P., González-Horta C., Corona Y. y Sanin L.H. (2004). Relation between pesticide exposure and intrauterine growth retardation. Chemosphere 55 (10), 1421-1427. DOI: 10.1016/j.chemosphere.2003.11.027

Leyva-Morales J.B., García de la Parra L.M., BastidasBastidas P.J., Astorga-Rodríguez J.E., Bejarano-Rodríguez J., Cruz-Hernández A., Martínez-Rodríguez I.E. y Betancourt-Lozano M. (2014). Uso de plaguicidas en un valle agrícola tecnificado en el noroeste de México. Rev. Int. Contam. Ambie. 30 (3), 247-261.

Leyva-Morales J.B., Valdez-Torres J.B., Bastidas-Bastidas P.J. y Betancourt-Lozano M. (2015). Validation and application of a multi-residue method, using accelerated solvent extraction followed by gas chromatography, for pesticides quantification in soil. J. Chromatogr. Sci. 53 (10), 1623-1630. DOI: 10.1093/chromsci/bmv063

Leyva-Morales J.B., Martínez-Rodríguez I.E., BastidasBastidas P.J. y Betancourt- Lozano M. (2017a). Plaguicidas altamente peligrosos utilizados en el Valle de Culiacán, Sinaloa. En: Los plaguicidas altamente peligrosos en México. (Bejarano-Gonzalez F. Ed.). RAPAM, CIAD, Red Temática de Toxicología de Plaguicidas, UAEMEX, INIFAP, UCCS, IPEN, PNUD. México, pp: 162-172. 
Leyva-Morales J.B., Valdez-Torres J.B., Bastidas-Bastidas P.J., Angulo- Escalante M.A., Sarmiento-Sánchez J.I., Barraza-Lobo A.L., Olmeda-Rubio C. y ChaidezQuiroz C. (2017b). Monitoring of pesticides residues in northwestern Mexico rivers. Acta Universitaria 27(1), 45-54. DOI: 10.15174/au.2017.1203

Lima A. y Vega L. (2005). Methyl-parathion and organophosphorous pesticide metabolites modify the activation status and interleukin-2 secretion of human peripheral blood mononuclear cells. Toxicol Lett. 158 (1), 30-38. DOI: 10.1016/j.toxlet.2005.02.010

López-Guzmán D., Yáñez-Estrada L., Athanasiadou M., Bergman A., Herrera C. y Díaz-Barriga F. (2006). Determinación de los niveles de DDT, DDE y DDE$\mathrm{MeSO}_{2}$ en leche materna y sangre de poblaciones contaminadas por DDT en México. Acta Toxicológica Argentina14, 34-36.

Lugo-Ibarra K.C., Daesslé L.W., Macías-Zamora J.V. y Ramírez-Álvarez N. (2011). Persistent organic pollutants associated to water fluxes and sedimentary processes in the Colorado River delta, Baja California, México. Chemosphere 85 (2), 210-217.

DOI: 10.1016/j.chemosphere.2011.06.030

Macías-Zamora J.V., Ramírez-Álvarez N. y HernándezGuzmán F.A. (2014). Ocurrente of PBDEs in marine sediments at Todos Santos bay and Punta Banda estuary. Organohalogen Compounds76, 857-860.

DOI: $10.13140 / 2.1 .2984 .9924$

Marina C.F., Bond J.G., Muñoz J., Valle J., Novelo-Gutiérrez R. y Williams T. (2014). Efficacy and non-target impact of spinosad, Bti and temephos larvicides for control of Anopheles spp. in an endemic malaria region of southern México. Parasite. Vector. 7 (55)1-10.

DOI: $10.1186 / 1756-3305-7-55$

Marsili L. y Focardi S. (1997). Chlorinated hydrocarbon (HCB, DDTs and PCBs levels in cetaceans stranded along the Italian coasts: an overview. Environ. Monit. Assess. 45 (2), 129-180.

DOI: 10.1023/A:1005786627533

Martínez-Luna G., Mejia-Sanchez F., Serment-Guerrero J.H. y Castillo-Cadena J. (2014). Quality spermatic alterations in floriculturists exposed to pesticides in Villa Guerrero, State of Mexico. Am. J. Agr. Forest. 2 (6), 284-288. DOI: 10.11648/j.ajaf.20140206.19

Martínez-Salinas R.I., Pérez-Maldonado I.N., Batres-Esquivel L.E., Flores-Ramírez R., Díaz-Barriga F. (2004). Assessment of DDT, DDE, and 1-hydroxypyrene levels in blood and urine samples in children from Chiapas México. Environ. Sci. Pollut. R. 19 (7), 2658-2656. DOI: $10.1007 / \mathrm{s} 11356-012-0758-7$

Martínez-Salinas R.I., Díaz-Barriga F., Batres-Esquivel L.E. y Pérez-Maldonado I.N. (2011). Assessment of the levels of DDT and its metabolites in soil and dust samples from Chiapas, México. Bull. Environ. Contam. Tox. 86 (1),33-37.

DOI: $10.1007 / \mathrm{s} 00128-010-0174-y$

Martínez-Tabche L., Galar C.I., Ramírez M.B., Morales R.A. y German F.C. (1994). Parathion effect on acetylcholinesterase from fish through an artificial trophic chain: Ankistrodesmus falcatus-Moina macrocopaOreochromis hornorum. Bull. Environ. Contam. Tox. 52 (3), 360-366. DOI: 10.1007/BF00197822

Martínez-Valenzuela C., Gómez-Arroyo S., VillalobosPietrini R., Waliszewski S., Calderón-Segura M.E., Félix-Gastélum R. y Álvarez-Torres A. (2009). Genotoxic biomonitoring of agricultural workers exposed to pesticides in the north of Sinaloa State, México. Environ. Int. 35 (8), 1155-1159.

DOI: $10.1016 /$ j.envint.2009.07.010

Melgar C., Geissen V., Cram S., Sokolov M., Bastidas P. y Ruíz-Suárez L.E. (2008). Pollutants in drainage channels following long-term application of mancozeb to banana plantations in southeastern México. J. Soil. Sci. Plant. Nutr. 171 (4), 597-604.

DOI: 0.1002/jpln.200700171

Mellink E., Riojas-López M.E. y Luévano-Esparza J. (2009). Organchlorine content and shell thickness in brown booby (Sula leucogaster) eggs in the Gulf of California and the southern Pacific coast of Mexico. Environ Pollut. 157 (7), 2184-2188.

DOI: 10.1016/j.envpol.2009.02.001

Medina-Díaz I.M., Rubio-Ortíz M., Martínez-Guzmán M.C., Dávalos-Ibarra R.L., Rojas-García A.E., Robledo-Marenco M.L., Barrón-Vivanco B.S., GirónPérez M. I. y Elizondo G. (2011). Organophosphate pesticides increase the expression of alpha glutathione S-transferase in HepG2 cells. Toxicol. In Vitro, 25 (8), 2074-2079. DOI: 10.1016/j.tiv.2011.08.010

Medina-Díaz I.M., Ponce-Ruiz N., Ramírez-Chávez B., Rojas-García A.E., Barrón-Vivanco B.S., Elizondo G. y Bernal-Hernández Y.Y. (2017). Downregulation of human paraoxonase 1 (PON1) by organophosphate pesticides in HepG2 cells. Environ. Toxicol. 32 (2), 490-500. DOI: 10.1002/tox.22253

Meléndez-Camargo M.A. y Hernández-López S. (1998). Effect of cadmium and parathion on renal function in rat. In Proc. West. Pharmacol. Soc. 41, 65-68. PMID: 9836245

Montes A.M., González-Farías F.A. y Botello A.V. (2012). Pollution by organochlorine pesticides in NavachisteMacapule, Sinaloa, Mexico. Environ. Monit. Assess. 184 (3), 1359-1369. DOI: 10.1007/s10661-011-2046-2

Mora M.A. y Anderson D.W. (1991). Seasonal and geographical variation of organochlorine residues in birds from northwest Mexico. Arch. Environ. Con. Tox. 21 (4), 541-548. DOI: 10.1007/BF01183876 
Mora M.A. (2008). Organochlorine pollutants and stable isotopes in resident and migrant passerine birds from northwest Michoacán, México. Arch. Environ. Con. Tox. 55 (3), 488-495. DOI: $10.1007 / \mathrm{s} 00244-007-9124-\mathrm{z}$

Mora M.A., Baxter C., Sericano J.L., Montoya A.B., Gallardo J.C. y. Rodríguez-Salazar J.R. (2011). PBDEs, PCBs, and DDE in eggs and their impacts on aplomado falcons (Falco femoralis) from Chihuahua and Veracruz, México. Environ. Pollut. 159 (12), 3433-3438. DOI: 10.1016/j.envpol.2011.08.025

Moreno-Villa E.D., Aldana-Madrid M.L., SilveiraGramont M.I., Rodríguez-Olibarría G., ValenzuelaQuintanar A.I. y Meza-Montenegro M. (2012). Análisis de piretroides en suelo y agua de zonas agrícolas y urbanas de los valles del Yaqui y Mayo. Rev. Int. Contam. Ambie. 28 (4), 303-310.

Niño-Torres C.A., Zenteno-Savín T., Gardner S.C. y Urbán G. (2009). Organochlorine pesticides and polychlorinated biphenyls in fin whales (Balaenoptera physalus) from the Gulf of California. Environ. Toxicol. 25 (4), 381-390. DOI: 10.1002/tox.20508

Nuñez G.M.A., Estrada I. y Calderon-Aranda E.S. (2002). DDT inhibits the functional activation of murine macrophages and decreases resistance to infection by Mycobacterium microti. Toxicology. 174 (3), 201-210. DOI: $10.1016 / \mathrm{S} 0300-483 X(02) 00078-1$

Oropeza-Hernández L.F., Sierra-Santoyo A., Cebrián M.E., Manno M. y Albores A. (2001). Ovariectomy modulates the response of some cytochrome P450 isozymes to lindane in the rat. Toxicol. Lett. 124 (1), 91-99. DOI: 10.1016/S0378-4274(01)00383-6

Ortega-Martínez L.D., Martínez-Valenzuela C., Huerta de la Peña A., Ocampo- Mendoza J., Sandoval-Castro E. y Jaramillo-Villanueva J.L. (2014). Uso y manejo de plaguicidas en invernaderos de la región norte del estado de Puebla, México. Acta Universitaria 24 (3), 3-12. DOI: 10.15174.au.2014.570

Osorio-Valencia E., Torres-Sánchez L., López-Carrillo L., Cebrián M.E., Rothenberg S.J., Hernández Chávez M.C. y Schnaasa L. (2015). Prenatal p,p'-DDE exposure and establishment of lateralization and spatial orientation in Mexican preschooler. Neurotoxicology 47, 1-7. DOI: 10.1016/j.neuro.2014.12.011

Osuna-Flores I. y Riva M.C. (2002). Organochlorine pesticide residue concentrations in shrimps, sediments, and surface water from bay of Ohuira, Topolobampo, Sinaloa, Mexico. Bull. Environ. Contam. Tox. 68 (4), 532-539. DOI: $10.1007 / \mathrm{s} 001280287$

Osuna-López J.I., Frías-Espericueta M.G., López-López G., Izaguirre-Fierro G., Zazueta-Padilla H., AguilarJuárez M., Correa-González E.M., Bautista-Covarrubias J.C., Cervantes-Atondo J.A., Sánchez-Osuna L. y Voltolina D. (2014). Niveles de concentración de pesticidas organoclorados en moluscos bivalvos del noroeste de México. En: Pacífico Mexicano. Contaminación e impacto ambiental: diagnóstico y tendencias. (A.V. Botello, F. Páez-Osuna, L. Méndez-Rodríguez, M. Betancourt-Lozano, S. Álvarez-Borrego y R. LaraLara, Eds.). uac, unam-icmyl, ciad-mazatlán, cibnor, cicese. México, pp: 33-42.

Ortíz D., Yáñez L., Gómez H., Martínez-Salazar J.A. y Díaz-Barriga F. (1995). Acute toxicological effects in rats treated with a mixture of commercially formulated products containing Methyl Parathion and Permethrin. Ecotox. Environ. Safe. 32 (2), 154-158.

DOI: 10.1006/eesa.1995.1096

Palacios-Nava M.E., García de la Torre G.S y Paz-Román M.P. (2009). Determinación de niveles basales de colinesterasa en jornaleros agrícolas. Rev. Fac. Med 52 (2), 63-68.

Pardío V., Martínez D., Flores A., Romero D., Suárez V., López K. y Uscanga R. (2012). Human health risk of dietary intake of organochlorine pesticide residues in bovine meat and tissues from Veracruz, México. Food. Chem. 135 (3), 1873-1893.

DOI: 10.1016/j.foodchem.2012.06.079

Pérez-Cogollo L.C., Rodríguez-Vivas R.I., DelfínGonzález H., Reyes-Novelo E. y Ojeda-Chi M.M. (2015). Lethal and sublethal effects of ivermectin on Onthophagus landolti (Coleoptera: Scarabaeidae). Enviro. Entomol. 44 (6), 1634-1640.

DOI: $10.1093 / \mathrm{ee} / \mathrm{nvv} 139$

Pérez-Herrera N., Polanco-Minaya H., Salazar-Arredondo E., Solís-Heredia M.J., Hernández-Ochoa I., RojasGarcía E., Alvarado-Mejía J., Borja-Aburto V.H. y Quintanilla-Vega B. (2008). PON1Q192R genetic polymorphism modifies organophosphorous pesticide effects on semen quality and DNA integrity in agricultural workers from southern México. Toxicol. Appl. Pharm. 230 (2), 261-268.

DOI: 10.1016/j.taap.2008.02.021

Pérez-Legaspi I.A., Quintanar J.L. y Rico-Martínez R. (2012). Comparing toxicity endpoints on Lecane quadridentata (Rotifera: Monogononta) exposed to two anticholinesterases pesticides. Environ. Toxicol. 27 (9), 518-525.

DOI: $10.1002 /$ tox.20668

Pérez-Maldonado I.N., Díaz-Barriga F., De la Fuente H., González-Amaro R., Calderón J. y Yañez L. (2004). DDT induces apoptosis in human mononuclear cells in vitro and is associated with increased apoptosis in exposed children. Environ. Res. 94 (1), 38-46. DOI: 10.1016/S0013-9351(03)00112-9

Pérez-Maldonado I.N., Athanasiadou M., Yáñez L., González-Amaro R., Bergman A. y Díaz-Barriga F. 
(2006). DDE-induced apoptosis in children exposed to the DDT metabolite. Sci. Total Environ. 370(2), 343-351. DOI: 10.1016/j.scitotenv.2006.06.026

Pérez-Olvera M.A., Navarro-Garza H., Flores-Sánchez D., Ortega-García N. y Tristán-Martínez E. (2017). Plaguicidas altamente peligrosos utilizados en el Bajío de Guanajuato. En: Los plaguicidas altamente peligrosos en México. (Bejarano-González F. Ed.). RAPAM, CIAD, Red Temática de Toxicología de Plaguicidas, UAEMEX, INIFAP, UCCS, IPEN, PNUD. México, pp: 184-202.

Pineda S., Budia F., Schneider M.I., Gobbi A., Viñuela E., Valle J. y Del Estal P. (2004). Effects of two biorational insecticides, spinosad and methoxyfenozide, on Spodoptera littoralis (Lepidoptera: Noctuidae) under laboratory conditions. J. Econ. Entomol. 97 (6), 19061911. DOI: 10.1603/0022-0493-97.6.1906

Piña-Guzmán B., Sánchez-Gutiérrez M., Marchetti F., Hernández-Ochoa I., Solis-Heredia M.J. y QuintanillaVega B. (2009). Methyl-parathion decreases sperm function and fertilization capacity after targeting spermatocytes and maturing spermatozoa. Toxicol. Appl. Pharm. 238 (2), 141-149.

DOI: $10.1016 /$ j.taap.2009.05.008

Plimmer J.R. (2001). Application of pesticides to crops (G.A. Matthews Ed.), Imperial College Press, London, 1999 pp. 325. DOI: 10.1002/1526-4998(200101)57:1<102::AIDPS278>3.0.CO;2-8

Prado G., Bhalli J.A. y Marcos R. (2009). Genotoxicity of heptachlor and heptachlor epoxide in human TK6 lymphoblastoid cells. Mutat. Res. 673 (2), 87-91.

DOI: $10.1016 /$ j.mrgentox.2008.12.002

Ramos-Chávez L.A., Sordo M., Calderón-Aranda E., Castañeda-Saucedo E., Ostrosky-Wegman P. y Moreno-Godínez M.E. (2015). A permethrin/allethrin mixture induces genotoxicity and cytotoxicity in human peripheral blood lymphocytes. J. Toxicol. Env. Heal. A. 78 (1), 7-14. DOI: 10.1080/15287394.2015.956025

Recio R., Robbins W.A., Ocampo-Gómez G., BorjaAburto V. y Morán-Martínez J. Froines J.R., García Hernández R.M. y Cebrián M.E. (2001). Organophosphorous pesticide exposure increases the frequency of sperm sex null aneuploidy. Environ. Health Persp. 109 (12), 31-34. DOI: $10.2307 / 3454745$

Recio R., Ocampo-Gómez G., Morán-Martínez J., BorjaAburto V., López-Cervantes M., Uribe M., TorresSánchez L. y Cebrián M.E. (2005). Pesticide exposure alters follicle-stimulating hormone levels in mexican agricultural workers. Environ. Health Persp. 113 (9),1160-1163. DOI: 10.1289/ehp.7374

Rendón-Von Osten J., Soares A.M.V.M. y Guilhermino L. (2005). Black-bellied whistling duck (Dendrocygna autumnalis) brain cholinesterase characterization and diagnosis of anticholinesterase pesticide exposure in wild populations from Mexico. Environ. Toxicol. Chem. 24 (2),313-317. DOI:10.1897/03-646.1

Rendón-Von Osten J. e Hinojosa-Garro D. (2017). Uso de plaguicidas altamente peligrosos en Campeche. En: Los plaguicidas altamente peligrosos en México. (Bejarano-González F. Ed.). RAPAM, CIAD, Red Temática de Toxicología de Plaguicidas, UAEMEX, INIFAP, UCCS, IPEN, PNUD. México, pp:254-261.

Reyes-Montiel N.J., Santamaría-Miranda A., RodríguezMeza G.D., Galindo-Reyes J.G. y González-Ocampo H.A. (2013). Concentrations of organochlorine pesticides in fish (Mugil cephalus) from a coastal ecosystem in the southwestern Gulf of California. Biol. Environ. 113B (3),1-11. DOI: 10.3318/BIOE.2013.25

Rivera-Rodríguez L.B. y Rodríguez-Estrella R. (2011). Incidence of organochlorine pesticides and the health condition of nestling ospreys (Pandion haliaetus) at laguna San Ignacio, a pristine area of Baja California Sur, México. Ecotoxicology 20 (1), 29-38.

DOI: $10.1007 / \mathrm{s} 10646-010-0553-5$

Robledo-Marenco M.L., Botello A.V., Romero-Bañuelos C.A. y Díaz-González G. (2006). Presence of persistent organochlorine pesticides in estuaries of the subtropical Mexican Pacific. Int. J. Environ. Pollut. 26 (1-3), 284-294. DOI: 10.1504/IJEP.2006.009112

Robles-Mendoza C., Zúñiga-Lagunes S.R., de León-Hill C.A.P., Hernández-Soto J. y Vanegas-Pérez, C. (2011). Esterases activity in the axolotl Ambystoma mexicanum exposed to chlorpyrifos and its implication to motor activity. Aquat. Toxicol. 105 (3), 728-734.

DOI: 10.1016/j.aquatox.2011.09.001

Rodas-Ortíz J.P., Ceja-Moreno V., González-Navarrete R.L., Alvarado-Mejía J., Rodríguez-Hernández M.E. y Gold-Bouchot G. (2008). Organochlorine pesticides and polychlorinated biphenyls levels in human milk from Chelem, Yucatán, México. Bull. Environ. Contam. Tox. 80 (3), 255-259.

DOI: $10.1007 / \mathrm{s} 00128-007-9356-7$

Rodríguez-Dozal S., Riojas Rodríguez H., HernándezÁvila M., Van Oostdam J., Weber J.P., Needham L.L. y Trip L. (2012). Persistent organic pollutant concentrations in first birth mothers across Mexico. J. Expo. Sci. Env. Epid. 22 (1), 60-69.

DOI: $10.1038 /$ jes.2011.31

Rojas-García A.E., Medina-Díaz I.M., Robledo-Marenco M.L., Barrón-Vivanco B.S., Girón-Pérez M.I., Velázquez-Fernández J.B., González-Arias C.A., Albores-Medina A., Quintanilla-Vega B., OstroskyWegman P., Rojas-García M.C., Pérez-Herrera N.E., López-Flores J.F. (2011). Hematological, biochemical effects, and self-reported symptoms in pesticide retailers. J. Occup. Environ. Med. 53 (5),517-521. DOI: $10.1097 / \mathrm{JOM} .0 \mathrm{~b} 013 \mathrm{e} 318215 \mathrm{fbf} 2$ 
Romero-Navarro G., López-Aceves T., Rojas-Ochoa A. y Fernández-Mejía C. (2006). Effect of dichlorvos on hepatic and pancreatic glucokinase activity and gene expression, and on insulin mRNA levels. Life. Sci. 78 (9), 1015-1020. DOI: 10.1016/j.lfs.2005.06.010

Romieu I., Hernandez-Avila M., Lazcano-Ponce E., Weber J.P. y Dewaill E. (2000). Breast cancer, lactation history, and serum organochlorines. Am. J. Epidemiol.152 (4), 263-270.

DOI: $10.1093 /$ aje/152.4.363

Rosales M.T.L. y Escalona R.L. (1983). Organochlorine residues in organisms of two different lagoons of northwest México. Bull. Environ. Contam. Tox. 30 (1), 456-463. DOI: 10.1007/BF01610160

Roque A., Abad S., Betancourt-Lozano M., García de la Parra L.M., Baird D., Guerra-Flores A.L. y Gomez-Gil B. (2005). Evaluation of the susceptibility of the cultured shrimp Litopenaeus vannamei to vibriosis when orally exposed to the insecticide methyl parathion. Chemosphere 60 (1), 126-134.

DOI: 10.1016/j.chemosphere.2005.01.008

Salas J.H., González M.M., Noa M., Pérez N.A., Díaz G., Gutiérrez R., Zazueta H. y Osuna I. (2003). Organophosphorus pesticide residues in Mexican commercial pasteurized milk. J. Agric. Food Chem. 51 (15), 44684471. DOI: $10.1021 / \mathrm{jf020942 \textrm {i }}$

Sánchez-Garayzar A.B., Bahamonde P.A., Martyniuk C.J., Betancourt M. y Munkittrick K.R. (2016). Hepatic gene expression profiling in zebrafish (Danio rerio) exposed to the fungicide chlorothalonil. Comp. Biochem. Phys. D. 19, 102-111. DOI: 10.1016/j.cbd.2016.04.004

Sarma S.S.S., Nandini S., Gama-Flores J.L. y FernándezAraiza M.A. (2001). Population growth of Euchlanis dilatata (Rotifera): combined effects of methyl parathion and food (Chlorella vulgaris). J. Environ. Sci. Heal. B. 36 (1), 43-54. DOI: 10.1081/PFC-100000915

Schettino B., Gutiérrez R., Ortiz R., Vega S., Urban G. y Ramírez A. (2013). Residues of legacy organochlorine contaminants in the milk of Alpine and Saanen goats from the central region of Mexico. Bull. Environ. Contam. Tox. 91 (2), 154-159.

DOI: $10.1007 / \mathrm{s} 00128-013-1005-8$

Schilmann A., Lacasaña M., Blanco-Muñoz J., AguilarGarduño C., Salinas-Rodríguez A., Flores-Aldana M., Cebrián M.E. (2009). Identifying pesticide use patterns among flower growers to assess occupational exposure to mixtures. Occup. Environ. Med. 67 (5), 323-329. DOI: 10.1136/oem.2009.047175

Seyhi B., Drogui P., Gortares-Moroyoqui P., EstradaAlvarado M.I. y Álvarez L.H. (2013). Adsorption of an organochlorine pesticide using activated carbon produced from an agro-waste material. J. Chem. Technol. Biot. 89 (12), 1811-1816. DOI: 10.1002/jctb.4256
Segura P., Chávez J., Montaño L.M., Vargas M.H., Delaunois A., Carbajal V. y Gustin P. (1999). Identification of mechanisms involved in the acute airway toxicity induced by parathion. N-S Arch. Pharmacol. 360 (6), 699-710. DOI: 10.1007/s002109900101

SEMARNAT (2010). NORMA Oficial Mexicana NOM059-SEMARNAT-2010, Protección ambiental-Especies nativas de México de flora y fauna silvestres Categoría de riesgo y especificaciones para su inclusión, exclusión o cambio-Lista de especies en riesgo. Secretaría de Medio Ambiente, Recursos Naturales y Pesca. Diario Oficial de la Federación. 30 de diciembre de 2010.

Teng M., Zhang H., Fu Q., Lu X., Chen J. y Wei F. (2013). Irrigation induced pollution of organochlorine pesticides and polychlorinated biphenyls in paddy field ecosystem of Liaohe River Plain, China. Environ. Chem. 58 (15), 1751-1759. DOI: 10.1007/s11434-013-5815-1

Thompson G.D., Dutton R. y Sparks T.C. (2000). Spinosad a case study: an example from a natural products discovery programme. Pest. Manag. Sci. 56 (8), 696-702. DOI: 10.1002/1526-4998(200008)56:8<696::AIDPS182>3.0.CO;2-5

Toledo-Ibarra G.A., Díaz-Resendiz K.J.G., PavónRomero L., Rojas-García A.E., Medina-Díaz I.M. y Girón-Pérez, M.I. (2016). Effects of diazinon on the lymphocytic cholinergic system of Nile tilapia fish (Oreochromis niloticus). Vet. Immunol. Immunop. 176, 58-63.

DOI: $10.1016 /$ j.vetimm.2016.05.010

Torres-Arreola L., López-Carrillo L., Torres-Sánchez L., Cebrián M.E., Rueda C., Reyes R. y LópezCervantes M. (1999). Levels of dichloro-dyphenyltrichloroethane (DDT) metabolites in maternal milk and their determinant factors. Arch. Environ. Health. 54 (2), 124-129.

DOI: $10.1080 / 00039899909602247$

Torres-Sánchez L., Schnaas L., Rothenberg S.J., Cebrián M.E., Osorio-Valencia E., Hernández M.C., GarcíaHernández R.M. y López-Carrillo L. (2013). Prenatal $\mathrm{p}, \mathrm{p}^{\prime}$-DDE exposure and neurodevelopment among children 3.5-5 years of age. Environ. Health Persp. 121 (2), 263-268. DOI: 10.1289/ehp.1205034

Urióstegui-Acosta M., Hernández-Ochoa I., SánchezGutiérrez M., Piña-Guzmán B., Rafael-Vázquez L., Solís-Heredia M.J., Martínez-Aguilar G. y QuintanillaVega B. (2014). Methamidophos alters sperm function and DNA at different stages of spermatogenesis in mice. Toxicol. Appl. Pharm. 279 (3), 391-400.

DOI: 10.1016/j.taap.2014.06.017

Valdespino C. Huerta-Peña A.I., Pérez-Pacheco A. y Rendón-Von Osten J. (2015). Persistent organochlorine pesticides in two hylidae species from the La Antigua 
watershed, Veracruz, México. Bull. Environ. Contam. Tox. 94 (1), 17-22. DOI: 10.1007/s00128-014-1398-Z Valdovinos-Flores C., Gaspar-Ramírez O., Heras-Ramírez M.E., Lara-Álvarez C., Dorantes-Ugalde J.A., y Saldaña-Loza L.M. (2016). Boron and coumaphos residues in hive materials following treatments for the control of Aethina tumida Murray. PloS one 11 (4), 1-11.

DOI: 10.1371/journal.pone.0153551

Valdovinos-Núñez G.R., Quezada-Euán J.J.G., Ancona-Xiu P., Moo-Valle H., Carmona A. y Sánchez E.R. (2009). Comparative toxicity of pesticides to stingless bees (Hymenoptera: Apidae: Meliponini). J. Econ. Entomol. 102 (5), 1737-1742. DOI: 10.1603/029.102.0502

Vargas-González H.H., Méndez-Rodríguez L.C., GarcíaHernández J., Mendoza-Salgado R.A, Zenteno-Savín T. y Arreola-Lizárraga J.A. (2016). Persistent organic pollutants (POPs) in populations of the clam Chione californiensis in coastal lagoons of the Gulf of California. J. Environ. Sci. Heal. B. 51 (7), 435-445.

DOI: $10.1080 / 03601234.2016 .1159455$

Vargas-Medrano J., Sierra-Fonseca J.A., Arellano-Carrillo M. y Plenge-Tellechea F. (2011). Cypermethrin, deltamethrin and glyphosate affect the activity of the $\mathrm{Ca}^{2+-}$ ATPase from human erythrocyte. Tecnociencia Chihuahua 5 (3), 121-131.

DOI10.13140/RG.2.1.2397.4886

Vázquez-Moreno L., Langure A., Orantes C., Flores M.E. y Bermúdez M.C. (1999). Incidence of pesticide residues in adipose tissue of beef, pork and poultry from plants located in northwestern Mexico. J. Muscle Foods 10 (4), 295-303.

DOI: $10.1111 / \mathrm{j} .1745-4573.1999 . t b 00404 . x$

Velasco A., Hernández S., Ramírez M. y Ortíz I. (2014). Detection of residual organochlorine and organophosphorus pesticides in agricultural soil in Rio Verde region of San Luis Potosi, Mexico. J. Environ. Sci. Heal. B. 49 (7), 498-504. DOI: 10.1080/03601234.2014.896670

Vences-Mejía A., Gómez-Garduño J., Caballero-Ortega H., Dorado-González V., Nosti-Palacios R., LabraRuíz N. y Espinosa-Aguirre J.J. (2012). Effect of mosquito mats (pyrethroid-based) vapor inhalation on rat brain cytochrome P450s. Toxicol. Mech. Method. 22 (1), 41-46. DOI: 10.3109/15376516.2011.591448

Waliszewski S.M., Aguirre A.A., Infanzon R.M. y Siliceo J. (2000). Partitioning coefficients of organochlorine pesticides between mother blood serum and umbilical blood serum. Bull. Environ. Contam. Tox. 65 (3), 293299. DOI: $10.1007 / \mathrm{s} 0012800127$

Waliszewski S.M., Aguirre A.A., Infanzon R.M. y Siliceo J. (2002). Persistent organochlorine pesticide levels in maternal blood serum, colostrum, and mature milk. Bull. Environ. Contam. Tox. 68 (3), 324-331.

DOI: $10.1007 / \mathrm{s} 001280257$
Waliszewski S.M., Villalobos-Pietrini R., Gomez-Arroyo S. e Infanzon R.M. (2003). Persistent organochlorine pesticide levels in cow's milk samples from tropical regions of Mexico. Food Addit. Contam. 20 (3), 270275. DOI: $10.1080 / 0265203031000062091$

Waliszewski S.M., Bermudez M.T., Infanzon R.M., Silva C.S., Carvajal O., Trujillo P., Gómez-Arroyo S., Villalobos-Pietrini R., Saldaña V.A., Melo G., Esquivel S., Castro F., Ocampo H.,Torres J. y Hayward-Jones P.M. (2005). Persistent organochlorine pesticide levels in breast adipose tissue in women with malignant and benign breast tumors. Bull. Environ. Contam. Tox. 75 (4), 752-759. DOI: 10.1007/s00128-005-0815-8

Waliszewski S.M., Carvajal O., Gómez-Arroyo S., Amador-Munóz O., Villalobos-Pietrini R., HaywardJones M. y Valencia-Quintana R. (2008). DDT and $\mathrm{HCH}$ isomer levels in soils, carrot root and carrot leaf samples. Bull. Environ. Contam. Tox. 81 (4), 343-347. DOI: $10.1007 / \mathrm{s} 00128-008-9484-8$

Wong F., Alegría H.A. Jantunen L.M., Bidleman T.F., Salvador-Figueroa M.,Gold-Bouchot G.,Ceja-Moreno V.,Waliszewski S.M. e Infanzon M.R. (2008). Organochlorine pesticides in soils and air of southern Mexico: chemical profiles and potential for soil emissions. Atmos. Environ. 42 (33), 7737-7745.

DOI: 10.1016/j.atmosenv.2008.05.028

Yáñez L., Borja-Aburto V.H., Rojas E., de la Fuente H., González-Amaro R., Gómez H., Jongitud A.A. y Díaz-Barriga F. (2004). DDT Induces DNA damage in blood cells. studies in vitro and in women chronically exposed to this insecticide. Environ. Res. 94 (1), 18-24. DOI: 10.1016/S0013-9351(03)00047-1

Zepeda-Arce R., Rojas-García A.E., Benitez-Trinidad A., Herrera-Moreno J.F., Medina-Díaz I.M., BarrónVivanco B.S., Pier-Villegas G., Hernández-Ochoa I., Solis Heredia M.J., Bernal-Hernández Y.Y. (2017). Oxidative stress and genetic damage among workers exposed primarily to organophosphate and pyrethroid pesticides. Environ. Toxicol. 2 (6), 1754-1764.

DOI: $10.1002 /$ tox. 22398

Zúñiga-Violante E., Arellano-García E., Camarena-Ojinaga L., Daesslé-Heusser W., Von-Glascoe C., LeyvaAguilera J.C. y Ruiz-Ruiz B. (2012). Daño genético y exposición a plaguicidas en trabajadores agrícolas del Valle de San Quintín, Baja California, México. Rev. Salud Ambient. 12 (2), 93-101.

Zúñiga-Violante E., Daesslé L.W., Camarena-Ojinaga M.L., Gutiérrez-Galindo E.A. y Arellano-García M.E., (2015). Distribución de contaminantes orgánicos e inorgánicos en el valle agrícola de Maneadero, Baja California, México. Investigación Ambiental 7 (1), 13-24. 